\title{
Independent effects of the chemical and microstructural surface properties of polymer/ceramic composites on proliferation and osteogenic differentiation of human MSCs
}

Citation for published version (APA):

Sun, L., Danoux, C. B., Wang, Q., Pereira, D., Barata, D., Zhang, J., LaPointe, V., Truckenmuller, R., Bao, C., Xu, X., \& Habibovic, P. (2016). Independent effects of the chemical and microstructural surface properties of polymer/ceramic composites on proliferation and osteogenic differentiation of human MSCs. Acta Biomaterialia, 42, 364-377. https://doi.org/10.1016/j.actbio.2016.06.018

Document status and date:

Published: 15/09/2016

DOI:

10.1016/j.actbio.2016.06.018

Document Version:

Publisher's PDF, also known as Version of record

Document license:

Taverne

Please check the document version of this publication:

- A submitted manuscript is the version of the article upon submission and before peer-review. There can be important differences between the submitted version and the official published version of record. People interested in the research are advised to contact the author for the final version of the publication, or visit the DOI to the publisher's website.

- The final author version and the galley proof are versions of the publication after peer review.

- The final published version features the final layout of the paper including the volume, issue and page numbers.

Link to publication

\footnotetext{
General rights rights.

- You may freely distribute the URL identifying the publication in the public portal. please follow below link for the End User Agreement:

www.umlib.nl/taverne-license

Take down policy

If you believe that this document breaches copyright please contact us at:

repository@maastrichtuniversity.nl

providing details and we will investigate your claim.
}

Copyright and moral rights for the publications made accessible in the public portal are retained by the authors and/or other copyright owners and it is a condition of accessing publications that users recognise and abide by the legal requirements associated with these

- Users may download and print one copy of any publication from the public portal for the purpose of private study or research.

- You may not further distribute the material or use it for any profit-making activity or commercial gain

If the publication is distributed under the terms of Article 25fa of the Dutch Copyright Act, indicated by the "Taverne" license above, 
Full length article

\title{
Independent effects of the chemical and microstructural surface properties of polymer/ceramic composites on proliferation and osteogenic differentiation of human MSCs
}

\author{
Lanying Sun $^{\mathrm{a}, \mathrm{b}, \mathrm{c}, 1}$, Charlène B. Danoux ${ }^{\mathrm{c}, 1}$, Qibao Wang ${ }^{\mathrm{a}}$, Daniel Pereira ${ }^{\mathrm{c}, \mathrm{d}}$, David Barata ${ }^{\mathrm{c}, \mathrm{d}}$, Jingwei Zhang ${ }^{\mathrm{c}}$, \\ Vanessa LaPointe ${ }^{\mathrm{c}, \mathrm{d}}$, Roman Truckenmüller ${ }^{\mathrm{c}, \mathrm{d}}$, Chongyun Bao ${ }^{\mathrm{e}}$, Xin Xu ${ }^{\mathrm{b}}$, Pamela Habibovic ${ }^{\mathrm{c}, \mathrm{d}, *}$ \\ a Oral Implantology Center, Stomotology Hospital of Jinan, Jingliu Road 101, 250001 Jinan, China \\ ${ }^{\mathrm{b}}$ School of Stomatology, Shandong Provincial Key Laboratory of Oral Tissue Regeneration, Shangdong University, Wenhuaxi Road 44-1, 250012 Jinan, China

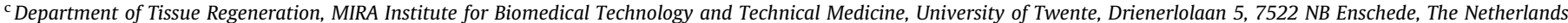 \\ ${ }^{\mathrm{d}}$ MERLN Institute for Technology-Inspired Regenerative Medicine, Maastricht University, Universiteitssingel 40, 6229 ER Maastricht, The Netherlands \\ ' State Key Laboratory of Oral Diseases, Sichuan University, Section 3 Ren Min Nan Lu 14, 610041 Chengdu, China
}

\section{A R T I C L E I N F O}

\section{Article history:}

Received 21 March 2016

Received in revised form 6 June 2016

Accepted 14 June 2016

Available online 16 June 2016

\section{Keywords:}

Calcium phosphate

Surface microstructure

hMSCs

Osteogenic differentiation

Property-biological response relationship

\begin{abstract}
A B S T R A C T
Within the general aim of finding affordable and sustainable regenerative solutions for damaged and diseased tissues and organs, significant efforts have been invested in developing synthetic alternatives to natural bone grafts, such as autografts. Calcium phosphate ( $\mathrm{CaP}$ ) ceramics are among widely used synthetic bone graft substitutes, but their mechanical properties and bone regenerative capacity are still outperformed by their natural counterparts. In order to improve the existing synthetic bone graft substitutes, it is imperative to understand the effects of their individual properties on a biological response, and to find a way to combine the desired properties into new, improved functional biomaterials. To this end, we studied the independent effects of the chemical composition and surface microstructure of a poly(lactic acid)/hydroxyapatite (PLA/HA) composite material on the proliferation and osteogenic differentiation of clinically relevant bone marrow-derived human mesenchymal stromal cells (hMSCs). While the molecular weight of the polymer and presence/absence of the ceramic phase were used as the chemical variables, a soft embossing technique was used to pattern the surfaces of all materials with either pits or pillars with identical microscale dimensions. The results indicated that, while cell morphology was affected by both the presence and availability of HA and by the surface microstructure, the effect of the latter parameter on cell proliferation was negligible. The osteogenic differentiation of hMSCs, and in particular the expression of bone morphogenetic protein 2 (BMP-2) and osteopontin (OP) were significantly enhanced when cells were cultured on the composite based on low-molecular-weight PLA, as compared to the high-molecular-weight PLA-based composite and the two pure polymers. The $O P$ expression on the low-molecular-weight PLA-based composite was further enhanced when the surface was patterned with pits. Taken together, within this experimental set up, the individual effect of the chemistry, and in particular of the presence of CaP, was more pronounced than the individual effect of the surface microstructure, although their combined effects were, in some cases, synergistic. The approach presented here opens new routes to study the interactions of biomaterials with the biological environment in greater depths, which can serve as a starting point for developing biomaterials with improved bioactivity.
\end{abstract}

\section{Statement of Significance}

The aim of the this study was to obtain insight into independent effects of the chemical composition and surface microstructure of a poly(lactic acid)/hydroxyapatite (PLA/HA) composite material on the morphology, proliferation and osteogenic differentiation of clinically relevant bone marrow-derived human mesenchymal stromal cells (hMSCs). While the need for synthetic alternatives for natural bone in bone regenerative strategies is rapidly increasing, the clinical performance of synthetic biomaterials needs

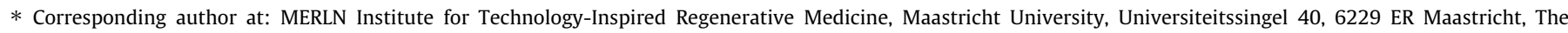
Netherlands.

E-mail address: p.habibovic@maastrichtuniversity.nl (P. Habibovic).

1 The authors contributed equally to the work.
} 
to be further improved. To do this successfully, we believe that a better understanding of the relationship between a property of a material and a biological response is imperative. This study is a step forward in this direction, and we are therefore convinced that it will be of interest to the readers of Acta Biomaterialia.

(c) 2016 Acta Materialia Inc. Published by Elsevier Ltd. All rights reserved.

\section{Introduction}

With a growing need for affordable regenerative strategies for damaged and diseased organs and tissues, recent research efforts have strongly focused on developing smart or instructive synthetic biomaterials that can exert a desired biological function in the body [1-4]. In the case of musculoskeletal regeneration, and more specifically the regeneration of bone tissue, the promise of synthetic bone graft substitutes is to offer an inexpensive replacement of natural bone grafts, i.e. auto-, allo- and xenografts that is also available in large quantities. Calcium phosphate $(\mathrm{CaP})$ ceramics, such as hydroxyapatite (HA), $\beta$-tricalcium phosphate and the mixtures of the two are among the most widely used and clinically most successful bone graft substitutes, owing to their close chemical resemblance to the mineral portion of bone [5]. Indeed, bone mineral has a structure similar to type $\mathrm{AB}$ carbonated CaP apatite [6].

Furthermore, bioactivity of $\mathrm{CaP}[7,8]$ in terms of osteoconduction, bone bonding and occasionally osteoinduction [9] makes them excellent candidates for bone repair and regeneration. Nevertheless, despite the use of CaPs for over four decades in the fields of orthopedics and dentistry, in general, their bioactivity is still considered inferior to that of their natural counterparts. Furthermore, the brittleness of CaP ceramics is a significant limitation for their use, in particular in load-bearing locations.

Various strategies have been considered to improve the bioactivity of bone graft substitutes, while retaining their synthetic character. In the case of CaP-based bone graft substitutes, variations in chemical composition have often been used as a means to control their in vivo degradation, and therewith, the hypothetical rate and the extent of new bone formation. For example, biphasic CaP ceramics in which the ratio between the CaP phases can be tuned to modulate their in vivo degradability were used to maximize their osteoinductive potential [10-12]. Also the architecture of such materials has been suggested to play an important role at different scales, varying from macroscopic porosity down to nanoscale surface topography [13-16]. More generally, surface topographical features of biomaterials have recently been elegantly shown to be a powerful tool to control cell fate [17-20]. Such studies commonly employ highly precise methods stemming from the field of micro- and nanotechnology and materials that are amenable to processing using such techniques. Therefore, the translation of data obtained from such studies to the behavior of bulk functional materials is not always trivial. CaP ceramics, for example, are relatively complex materials, with an intertwined set of physico-chemical properties. This makes it difficult to modify one property without thereby affecting one or more of the others. As a result, correlating any type of biological response to one or a combination of properties is difficult, and yet this is a very important step in the process of designing new bone graft substitutes with functionality equal to the autograft. In our earlier studies, we elaborated on the individual effects of calcium $\left(\mathrm{Ca}^{2+}\right)$ and inorganic phosphate $(\mathrm{Pi})$ ions, by developing composite materials consisting of a polymer and either a calcium- [21] or a phosphate salt $[21,22]$. More recently, an attempt was made to separate the chemical effect of $\mathrm{CaP}$ from the stiffness of the material, demonstrating the role of both properties in osteogenic differentiation of human periosteal derived progenitor cells [23].
In the present study, the focus was on the microstructural surface properties on the one hand, and the local $\mathrm{Ca}^{2+}$ and Pi concentrations on the other. To this end, a composite material consisting of poly(lactic acid) (PLA) and nanometer-sized HA powder with engineered surface features at the micrometer scale was used. In our recent study, the proof-of-concept was shown that such a surface-microstructured composite is useful for studying the independent effects of the presence of $\mathrm{CaP}$ and microstructure on the expression of osteogenic markers by hMSCs [24]. Ceramic/polymer composites are considered a promising family of biomaterials in which the bioactivity of CaPs and versatile mechanical properties of polymers are combined. This specific PLA/HA composite contains CaP in the same phase as that used for the production of CaP ceramic bone graft substitutes. Furthermore, its degradation rate and consequent release of $\mathrm{Ca}^{2+}$ and $\mathrm{Pi}$, can be controlled in a relatively facile fashion by varying the molecular weight of PLA, as the polymer with a lower molecular weight has been shown to degrade faster and thus release more ions than the polymer having a higher molecular weight [25]. In a number of studies, composite materials based on PLA and HA have shown to support attachment, growth and osteogenic differentiation of MSCs and (pre)osteoblasts [26-28]. In vivo, PLA/HA composites could successfully heal a $6 \mathrm{~mm}$ femoral intercondylar defect in rabbits and a critical-sized cranial defect in rats [29,30], and even osteoinductivity of PLA/HA composites was demonstrated upon intramuscular implantation in dogs or sheep $[25,31,32]$.

Another reason for choosing PLA/HA composite in the present study is its amenability to surface micropatterning using soft lithography, in contrast to classically sintered CaP ceramics. We used replica molding to generate materials with distinct surface topographies at the micrometer scale. Replica molding is a common molding-based soft lithography technique that has a long history of use in fabrication of microelectromechanical systems (MEMS) by the precise control of ordered structures such as pits, pillars, grooves, and wells at the micrometer scale [33-35]. Soft lithography techniques have been successfully used to transfer well-defined micro-sized patterns from silicon or stainless steel masters to surfaces of biomaterials [36-38], allowing the recreation of controlled microenvironments and an in depth study of the influence of surface properties on cell behavior [39,40].

We have previously shown that a comparison between a polymer and its composite with HA, with or without surface microstructure, is useful to distinguish between the chemical and the structural effects on cell differentiation [24]. Here, we hypothesized that both the molecular weight of PLA, which is known to affect the composite degradation rate and release of $\mathrm{Ca}^{2+}$ and $\mathrm{Pi}$, and the surface-microstructural features will both influence the growth and differentiation of hMSCs. To test this hypothesis, two distinct microscale topographies, namely pits and pillars with identical sizes were imprinted into two PLA/HA composites based on two molecular weights of PLA as well as in polymeric controls without CaP. The rationale behind the choice of these topographies was the previously suggested effect of concavities on processes related to bone formation [41-43]. HMSCs were cultured on these materials, and their attachment, proliferation and osteogenic differentiation were assessed, along with the analysis of $\mathrm{Ca}^{2+}$ and $\mathrm{Pi}$ concentrations and material degradation during culture. 


\section{Materials and methods}

\subsection{Preparation of PLA/HA composites and micropatterning of their surface}

Two types of composite materials were prepared, one using low-molecular-weight (55,000-59,000 Da) poly(D,L-lactic acid) (LPLA, ANaBior, France) and one using high molecular weight (400,000 Da) PLA (H-PLA, Purac, the Netherlands). HA powder was synthesized using a wet precipitation method, which was previously shown to result in phase-pure particles with a width of $69.9 \pm 12.8 \mathrm{~nm}$ and a length of $308.7 \pm 61.2 \mathrm{~nm}[25,44]$. To produce the composite material, a mixture of 50 wt.\% PLA and 50 wt.\% HA was prepared and extruded using a conical non-converging twinscrew extruder (Artecs BV, Enschede, the Netherlands) at a temperature of $150{ }^{\circ} \mathrm{C}$, using a screw speed of $100 \mathrm{rpm}$ with a 5-min premixing, as described previously [25]. Control materials made of L-PLA or H-PLA without HA were produced using the same procedure. Then, PLA/HA composites and PLA controls were shaped into pellets with a diameter of $10 \mathrm{~mm}$ using a metal frame mold and a heating press at $120^{\circ} \mathrm{C}$ (for L-PLA/HA composite and LPLA) or $150{ }^{\circ} \mathrm{C}$ (for H-PLA/HA composite and H-PLA) and $30 \mathrm{kN}$ for $5 \mathrm{~min}$.

Pulsed femtosecond laser micromachining (Lightmotif, Enschede, the Netherlands) was used to produce a stainless steel master containing 25 different topographies, including the pits used in this study. Inverse polydimethyl siloxane (PDMS) molds of the selected pits topography were prepared by casting the silicone elastomer base resin (Sylgard 184, Dow Corning, USA), mixed with the curing agent at a 10:1 ratio, over the stainless steel master. The PDMS precursor and master were then placed together under vacuum to evacuate air bubbles and left at ambient temperature for 2 days, followed by incubation at $50{ }^{\circ} \mathrm{C}$ to allow polymerization. Upon removal, the PDMS negative replica (thus with pillars) was used to produce a second PDMS replica (with pits) using the same method. Both PDMS replicas were subsequently used as molds to pattern surfaces of composite and polymer pellets by hot embossing at $120^{\circ} \mathrm{C}$ (for L-PLA/HA composite and L-PLA) or $150{ }^{\circ} \mathrm{C}$ (for H-PLA/HA composite and H-PLA) for 10 and 6 min for composites and polymers, respectively. The rationale for selecting the dimensions of pits and pillars $(15-20 \mu \mathrm{m}$ in the $\mathrm{x}-\mathrm{y}$ direction and depth/height of $4 \mu \mathrm{m}$ ) comparable to the single cell size was the previously demonstrated effect of (sub)cellular size topographical features on cell shape, and consequently on cell proliferation and/or differentiation $[20,45,46]$.

Samples embossed with a flat PDMS mold without topography served as controls. Gold-sputtered patterned surfaces were analyzed using scanning electron microscopy (SEM) in the secondary electron mode, with an acceleration voltage of $10 \mathrm{kV}$ for composites and $5 \mathrm{kV}$ for polymers. The SEM was equipped with an energy dispersive X-ray spectroscopy module (EDS; Apollo X, Ametek) that allowed elemental analysis of the surface. As a preparation for cell culture, the samples were placed in low-attachment 48well plates and fixed with O-rings. They were then immersed in 70\% isopropanol for 30 min with two refreshments every $10 \mathrm{~min}$, and after complete evaporation thoroughly washed with sterile phosphate-buffered saline (PBS).

\subsection{Cell culture on imprinted PLA/HA composites and polymers}

HMSCs were isolated from bone marrow aspirates obtained from a healthy donor after written informed consent and expanded as described previously $[47,48]$. In brief, bone marrow aspirates $(5-20 \mathrm{ml})$ were resuspended with $20 \mathrm{G}$ needles, plated at a density of $5 \times 10^{5}$ cells $\mathrm{cm}^{-2}$ and cultured in proliferation medium comprising $\alpha$-minimal essential medium (a-MEM; Gibco), 10\% fetal bovine serum (FBS; Lonza), $4 \mathrm{mM}$-glutamine (Gibco), $0.2 \mathrm{mM}$ ascorbic acid (Sigma Aldrich), $100 \mathrm{U} \mathrm{ml}^{-1}$ penicillin (Gibco), $100 \mu \mathrm{g} \mathrm{ml}^{-1}$ streptomycin (Gibco), and $1 \mathrm{ng} \mathrm{ml}^{-1}$ basic fibroblast growth factor (bFGF) (Instruchemie, the Netherlands). Cells were expanded at $37^{\circ} \mathrm{C}$ in a humidified atmosphere with $5 \% \mathrm{CO}_{2}$. Medium was refreshed twice weekly, and cells were subcultured until $80 \%$ confluency. This expansion procedure was previously shown to result in cells that are positive for typical markers of hMSCs including integrin CD29, matrix receptors CD44 and CD105, and stromal cell associated marker CD166 [47]. The passage 3 cells were used for all experiments.

Prior to cell seeding, the PLA/HA and PLA pellets were incubated overnight in either basic medium (BM; proliferation medium without bFGF) or in osteogenic medium (BM supplemented with $10 \mathrm{nM}$ dexamethasone, a known stimulator of osteogenic differentiation $[48,49])$ at $37^{\circ} \mathrm{C}$ in a humidified atmosphere with $5 \% \mathrm{CO}_{2}$. For the analysis of cell morphology, 4000 cells were seeded on each sample in BM. For the assessment of proliferation, osteogenic differentiation and gene expression of cells, and for the analysis of $\mathrm{Ca}^{2+}$ and Pi concentration and material surface changes during culture, 10,000 hMSCs were seeded on each sample and incubated in either BM or OM. The media were refreshed every 2-3 days.

\subsection{Cell morphology assessment}

Cell morphology assessment was performed after 3 days of culture in BM $(n=3$, except for flat L-PLA and pits-patterned H-PLA, where $n=2$ was used, because the third sample was damaged during processing). The samples were washed with PBS and fixed with $4 \%$ paraformaldehyde for $20 \mathrm{~min}$. To perform immunofluorescence staining and analysis, the samples were permeabilized with $0.1 \%$ Triton X-100 for 5 min and blocked with $1 \%$ bovine serum albumin (BSA) in PBS. Cell cytoskeleton was stained by phalloidin conjugated to Alexa Fluor 488 (1:60 dilution in 1\% BSA in PBS; Invitrogen), and DAPI (in 1\% BSA in PBS) was used to stain cell nuclei. Cell imaging on eight randomly selected areas of each sample was performed using fluorescence microscopy (BD Pathway 435, BD Biosciences). The analysis of the cell shape parameters was performed using CellProfiler (Broad Institute, USA) with built-in modules (MeasureObjectSizeShape), according to the detailed manual published previously [50]. This module measures several areaand shape features of identified objects and for this study, cell area, cell perimeter and minor axis length were selected. The number of cells used for the analysis varied between approximately 400 and 1400 for all the materials, except for flat H-PLA where the total number of cells was 64 .

\subsection{Cell proliferation and osteogenic differentiation}

Cell proliferation was assessed after 3, 7 and 14 days of culture $(n=4)$. Total DNA was quantified as a measure of cell number using CyQUANT Cell Proliferation Assay kit (Life Technologies) according to the manufacturer's protocol. In short, after 3 cycles of freeze/thaw at $-80^{\circ} \mathrm{C}, 500 \mu \mathrm{l}$ lysis buffer (lysis buffer provided in the kit diluted in a buffer of $\mathrm{NaCl}$-EDTA solution) was added to each well. The samples were ultrasonicated and incubated at room temperature for $1 \mathrm{~h}$. After centrifugation, the lysis buffer was collected and the DNA content was measured by mixing $100 \mu \mathrm{l}$ of the supernatant with the same volume of CyQuant GR dye in a 96 well micro-plate followed by incubation for $15 \mathrm{~min}$. Fluorescence measurements for DNA quantification were done at excitation and emission wavelengths of 480 and $520 \mathrm{~nm}$, respectively, using a spectrophotometer (Victor3, Perkin Elmer).

Alkaline phosphatase (ALP) activity, an early marker of osteogenic differentiation, was determined after 7 and 14 days of cul- 
ture $(\mathrm{n}=4)$ by using CDP-Star chemiluminescent substrate (Roche Applied Science), according to the manufacturer's protocol. In short, $10 \mu$ of the lysis buffer used for quantifying DNA content was mixed with $40 \mu \mathrm{l} \mathrm{CDP-star}$ reagent in a 96 well micro-plate and incubated for $30 \mathrm{~min}$. After incubation, chemiluminescence measurements were completed at $466 \mathrm{~nm}$. The ALP activity was normalized for the DNA content.

To evaluate the influence of surface topography and chemical composition of the samples on the expression of the markers of osteogenic differentiation at the mRNA level, hMSCs were cultured for 7 and 14 days $(n=3)$. Total RNA of the cells was extracted by using a combination of TRIzol (Invitrogen) and a Nucleospin ${ }^{\circledR}$ RNA isolation and purification kit (Macherey-Nagel $\mathrm{GmbH} \&$ Co.). $1 \mathrm{~mL}$ of TRIzol reagent was added to each well. Following one freeze/thaw cycle, $200 \mu \mathrm{L}$ chloroform was added, and after mixing and centrifugation the aqueous phase of each sample was collected and mixed with $350 \mu \mathrm{L} 70 \%$ ethanol before loading onto the RNA binding column of the NucleoSpin RNA II isolation kit. Subsequent steps were in accordance with the manufacturer's protocol.

First strand cDNA was synthesized using iScript (Bio-Rad). Quantitative real-time PCR was performed and CT values were normalized to the glyceraldehyde 3-phosphate dehydrogenase $(G A P D H)$ housekeeping gene and fold induction was calculated using the comparative $\Delta \Delta C T$ method. The expression of hMSCs cultured on flat H-PLA for 7 days in BM served as a calibrator. Primer sequences of the selected markers bone morphogenetic protein 2 (BMP-2), runt-related transcription factor 2 (Runx2), osteopontin (OP), ALP and collagen type 1 (Col-I) are given in Table 1.

\subsection{Quantification of $\mathrm{Ca}^{2+}$ and Pi concentration in cell culture medium}

Cell culture medium $(n=4)$ was collected during refreshments after 3, 7 and 14 days of culture. $\mathrm{Ca}^{2+}$ and Pi content of the medium was determined using QuantiChrom calcium assay kit and phosphate assay kit (BioAssay, USA), respectively, according to the manufacturer's protocol. Medium containing cells but not materials, and medium without either cells or materials served as controls. The absorbance was read with a spectrophotometer (Multiskan $^{\mathrm{TM}}$ GO, Thermo Scientific) at $612 \mathrm{~nm}$ and $620 \mathrm{~nm}$ for $\mathrm{Ca}^{2+}$ and Pi, respectively. At day 14 , the samples were evaluated using SEM and EDS as described above.

\subsection{Statistical analysis}

Cell proliferation and differentiation results were tested for statistical differences with factorial ANOVA, using the univariate general linear model in SPSS Statistics 22 (IBM). The model was selected via an iterative approach, first including all possible interactions and subsequently removing the non-significant interaction terms if the adjusted- $\mathrm{R}^{2}$ remained the same or decreased. The Bonferroni post-hoc test was used for pairwise comparisons between groups. Cell morphology results were compared using the 2-way ANOVA, followed by the Bonferroni post-hoc test for pairwise comparison. All results are presented as mean \pm SD. The level of statistical significance was set as $p<0.05$.

\section{Results}

\subsection{Characterization of micropatterned PLA and PLA/HA}

To investigate individual effects of surface microscale topography and chemical composition on the behavior of hMSCs, the surfaces of the four materials L-PLA/HA, H-PLA/HA, L-PLA and H-PLA were patterned by pits and by pillars, while flat materials served as controls.
Table 1

Primer sequences used for qPCR analysis.

\begin{tabular}{|c|c|}
\hline Gene & Gene primer sequences \\
\hline GAPDH & $\begin{array}{l}\text { 5'-CCATGGTGTCTGAGCGATGT } \\
\text { 5'-CGCTCTCTGCTCCTCCTGTT }\end{array}$ \\
\hline BMP2 & $\begin{array}{l}\text { 5'-GGTGATGTCCTCGTCTGTA } \\
\text { 5'-CCAAGTAAGTCCAACGAAAG }\end{array}$ \\
\hline Runx2 & $\begin{array}{l}\text { 5'-ACGGCGGGGAAGACTGTGC } \\
\text { 5'-ATGGCGGGTAACGATGAAAAT }\end{array}$ \\
\hline$O P$ & $\begin{array}{l}\text { 5'-GGTGATGTCCTCGTCTGTA } \\
\text { 5'-CCAAGTAAGTCCAACGAAAG }\end{array}$ \\
\hline$A L P$ & $\begin{array}{l}\text { 5'-TTCAGCTCGTACTGCATGTC } \\
\text { 5'-ACAAGCACTCCCACTTCATC }\end{array}$ \\
\hline COL-1 & $\begin{array}{l}\text { 5'-AGATCACGTCATCGCACAACA } \\
\text { 5'-AGGGCCAAGACGAAGACATC }\end{array}$ \\
\hline
\end{tabular}

SEM micrographs (Fig. 1) showed that all surfaces were successfully patterned with either pits or pillars. Both topographies had an oval shape and their dimensions were similar, with a major axis length of about $20 \mu \mathrm{m}$, minor axis length of about $15 \mu \mathrm{m}$, and center-tocenter distance of about $30 \mu \mathrm{m}$. The height of the pillars was measured to be $4.0 \pm 0.1 \mu \mathrm{m}$, which is expected to be the same as the depth of the pits. No differences in topographical dimensions were observed between the composites and the polymers, or between composites/polymers with a different molecular weight of PLA.

EDS spectra of the two composite materials showed pronounced calcium and phosphorus peaks (Fig. 2a, and b), which were absent in the spectra of the PLA samples (Fig. 2c and d). Elemental mapping of calcium and phosphorous demonstrated a homogenous distribution of the ceramic phase, independent of the molecular weight of PLA (Fig. 2e-h).

\subsection{Cell attachment and morphology}

Fluorescence microscopy images (Supplementary Fig. 1) of cells cultured for 3 days revealed that all materials, independent of the chemistry or topography, allowed the attachment of hMSCs. The cells on flat and pits-patterned surfaces displayed a well-spread morphology. In contrast, the spreading of cells grown on pillarspatterned surfaces was somewhat less pronounced. Based on these qualitative observations, no obvious differences were seen in cell morphology when different material chemistries are considered.

CellProfiler-based analysis of fluorescent micrographs confirmed that the three morphology parameters, i.e. cell area, cell perimeter and minor axis length were affected by the surface topography (Fig. 3). The strongest effect was observed on the composite materials, where cells cultured on pillars-patterned substrates consistently showed a lower area, perimeter and minor axis length than the cells cultured on flat or pits-patterned substrates. This was the case both for L-PLA/HA and H-PLA/HA. Furthermore, in the case of L-PLA/HA, the values for the three parameters observed on the flat substrate were significantly lower as compared to pits-patterned L-PLA/HA. These differences were not observed on high-molecular-weight composite. On the two polymers, the effect of topography was less pronounced. Nevertheless, on L-PLA, the pits-patterned substrate showed a higher cell area, perimeter and minor axis length than the pillars-patterned and flat substrate. Furthermore, the perimeter of the pillarspatterned L-PLA was higher than that of the flat control. In contrast to L-PLA, the cell area, cell perimeter and the minor axis length were higher on pillars-patterned H-PLA as compared to the pitspatterned and flat substrate.

The effects of substrate chemistry (i.e. presence/absence of CaP and low/high molecular weight of PLA) were also observed, but 
Pits
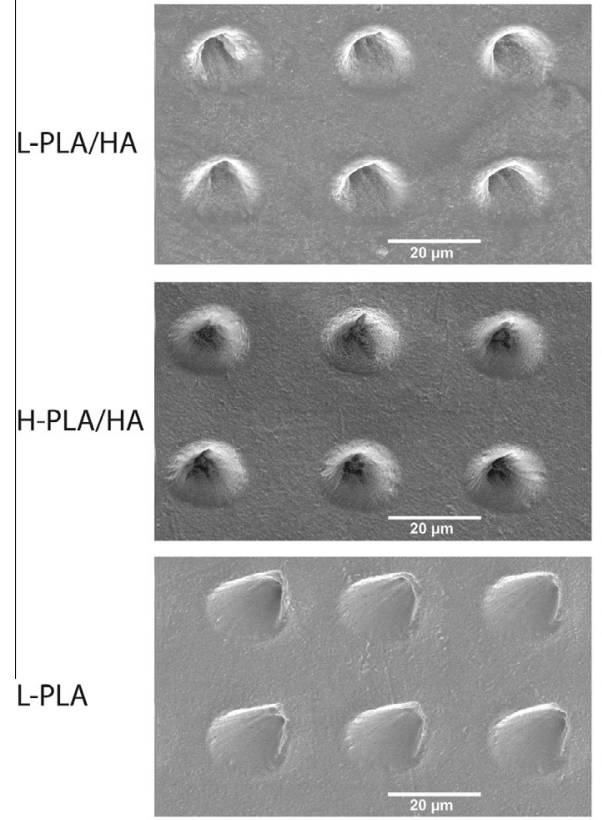

L-PLA

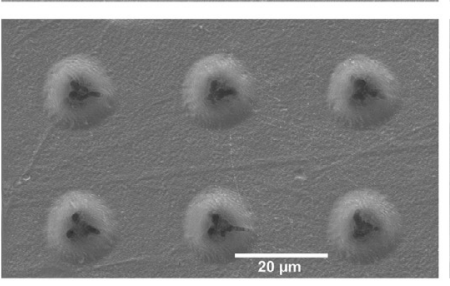

H-PLA
Pillars
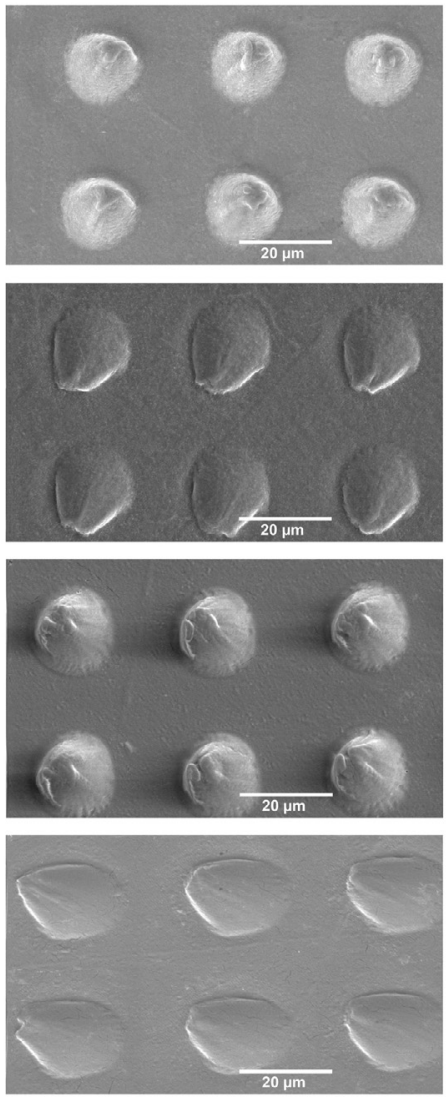

Flat
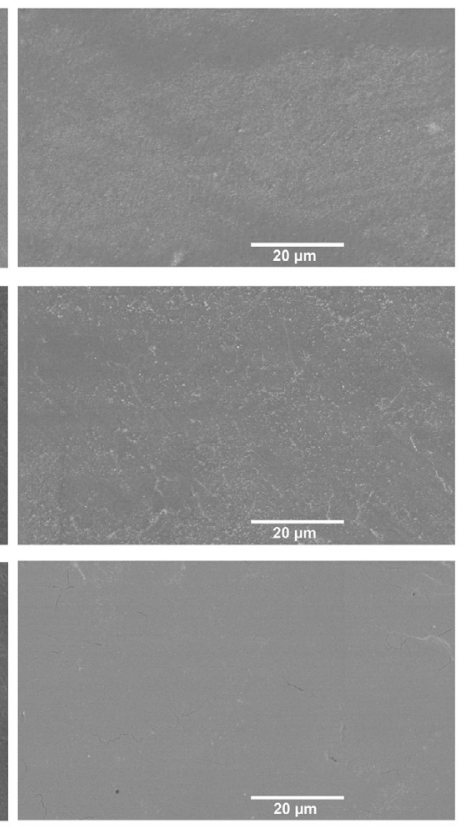
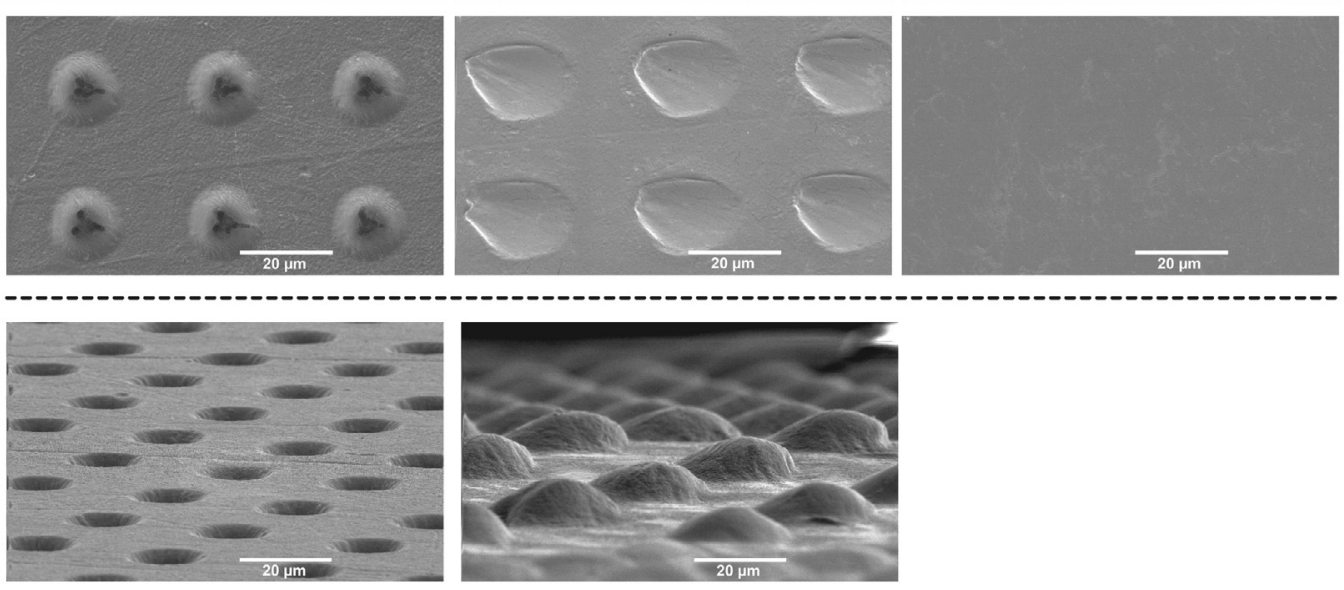

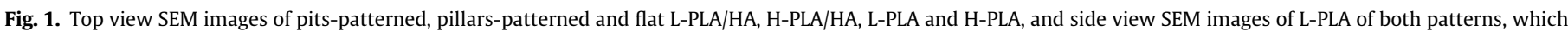

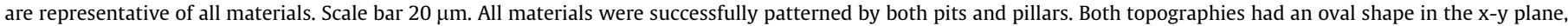

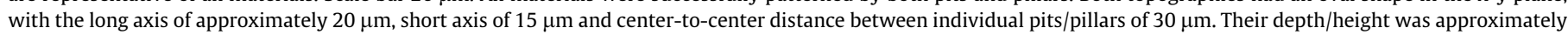
$4 \mu \mathrm{m}$.

were less pronounced as compared to the effect of surface topography. In general, differences between chemically different materials were small or non-existent on flat substrates, while on the patterned substrates, some significant differences were observed. For example, on pillars-patterned substrates, cells cultured on polymers showed higher values for the three morphology parameters than those cultured on composite materials. Furthermore, for pits-patterned substrates, the cell spreading on low-molecular weight polymer/composite appeared somewhat more pronounced than on their high-molecular weight counterparts.

Taken together, these data suggested the effect of both surface topography and substrate chemistry on the morphology of hMSCs.

\subsection{Cell proliferation on micropatterned PLA and PLA/HA}

The combined DNA quantity of cells cultured on different substrates for 3, 7 and 14 days was used as a measure of cell proliferation. The results showed that all substrates supported the growth of hMSCs over the 14-day culture period in both BM (Fig. 4) and OM (Supplementary Fig. 2).
In BM, an increase in DNA amount was observed between days 3 and 7 on all materials, after which it remained stable until day 14. Regarding the effect of the chemical composition, at day 3 , there was more combined DNA from cells cultured on L-PLA/HA than from cells cultured on H-PLA, for all topographies. After 7 days, cells cultured on either composite showed higher DNA values than those cultured on the polymers, independent of molecular weight or topography. The same observation was made at 14 days, with as additional difference that between L-PLA/HA and H-PLA/ HA. No significant effect of topography on DNA amount was observed after 14 days. The trend of cell proliferation in OM was in general similar to that in BM (Supplementary Fig. 2).

These data suggested that chemistry, and more specifically, the presence of CaP, had a positive effect on cell proliferation, whereas the effect of surface topography was negligible.

\subsection{Osteogenic differentiation of hMSCS on micropatterned PLA and PLA/HA}

Enzymatic ALP activity of cells cultured on different materials for 7 and 14 days was measured and normalized for DNA amount, 
a
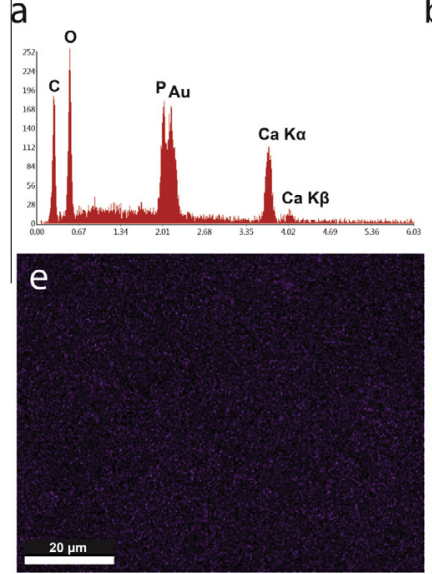

b
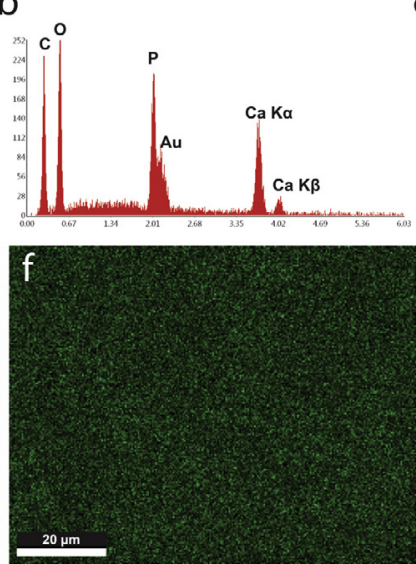

$c$
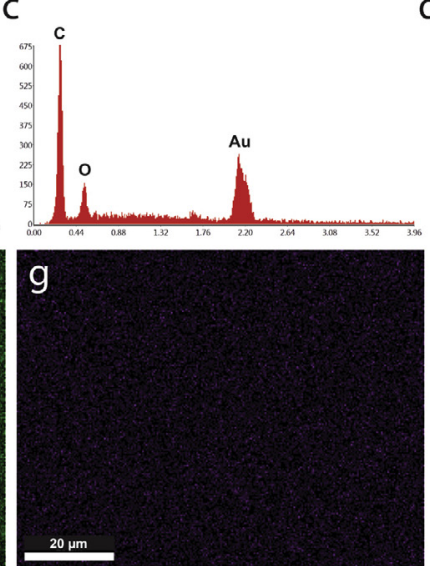

d
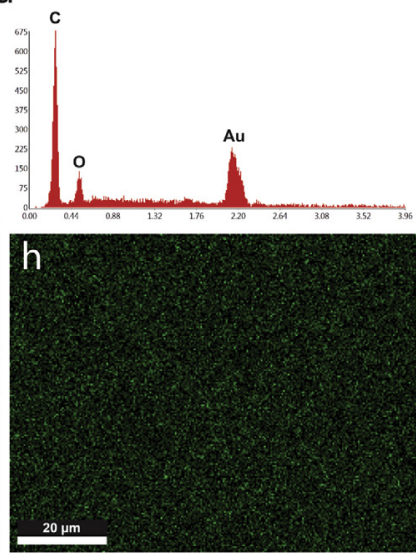

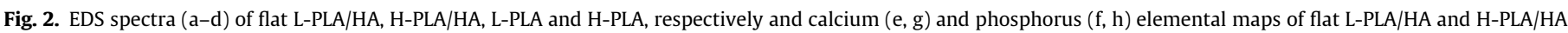

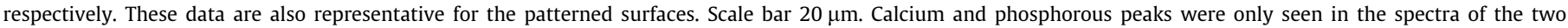

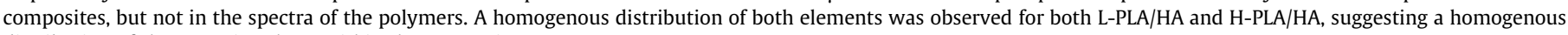
distribution of the ceramics phase within the composite.

as a marker of early osteogenic differentiation (Fig. 5 and Supplementary Fig. 3 for culture in BM and OM, respectively). Furthermore, the mRNA transcript expression of a set of markers of osteogenic differentiation (BMP-2, Runx2, ALP, Col-I and OP) was determined at the same time points (Fig. 6 and Supplementary Fig. 4, for culture in BM and OM, respectively).

In BM, at 7 days, the ALP activity of cells cultured on the two composites appeared somewhat higher as compared to the culture on the polymeric substrates, although no statistically significant differences were measured. ALP activity increased between 7 and 14 days for all conditions. At 14 days, cells cultured on H-PLA/HA showed significantly higher ALP values as compared to the other three chemistries. No significant topography effects were observed on ALP activity at 14 days. The ALP activity of the cells cultured in OM was in general higher than what was observed upon culture in $\mathrm{BM}$, with an increase between 7 and 14 days. The results of culture in OM showed a similar trend to that observed in BM; no significant differences among the materials at 7 days, and in general higher ALP activity on H-PLA/HA as compared to the other three chemistries at 14 days. A small effect of topography was seen on H-PLA/HA and L-PLA substrates (for more detailed information see Supplementary Information).

Regarding the mRNA transcript expression, in BM, it was generally observed that the expression of BMP-2, Runx2 and OP was upregulated on L-PLA/HA as compared to the other three chemistries, at both time points. The expression of $A L P$ on L-PLA/HA was higher than on H-PLA/HA for all topographies and at both time points, however, these differences were very small, with little biological relevance. At both 7 and 14 days, the mRNA expression of $B M P-2$ was significantly higher when cells were cultured on LPLA/HA as compared to the other three materials, and this difference was independent of the surface topography. The same effect was observed for the expression of Runx2 (although the fold change was only about 1.5 times), with the exception of the flat substrate at 14 days. Also the expression of $O P$ in cells cultured on pits-patterned L-PLA/HA was significantly elevated as compared to that of cells cultured on the other three pits-patterned substrates, at both time points. Differences in Col-1 expression were small, with a downregulation on H-PLA/HA as compared to the other three materials, for both patterned and unpatterned substrates.

The effect of topography was most pronounced on L-PLA/HA. $B M P-2$ expression was higher on pillars-patterned and on both pillars-and pits-patterned L-PLA/HA at 7 and 14 days, respectively. Similarly, the expression of Runx2 and $O P$ was higher on pitspatterned than on flat L-PLA/HA at both time points. In contrast, at day 14, the expression of $A L P$ on all patterned substrates was lower than on the flat substrates, although these differences were very small.

When culture in OM is considered, a general observation was that the addition of dexamethasone strongly suppressed the expression of BMP-2 and $O P$ at both 7 and 14 days, while it significantly increased the expression of $A L P$ at both time points as compared to BM. No obvious effect of OM was observed on the expression of Runx2 and Col-1. Furthermore, the effect of biomaterials properties, with an emphasis on chemistry, seemed less pronounced as compared to the culture in BM (for more detailed information, see Supplementary Information).

Taken together, while a mild effect of surface topography was observed on the ALP enzymatic activity of hMSCs, the main effect was due to the presence of CaP. Similarly, the expression of BMP2, OP and to a lesser extent Runx2 and Col-1 at the mRNA level was mainly affected by the chemical properties of the materials, with the composite made from L-PLA having the strongest positive effect. The topography played a role, although a less pronounced one, on the osteogenic differentiation of hMSCs as well.

\section{5. $\mathrm{Ca}^{2+}$ and Pi concentration profile and material surface changes during cell culture}

Ionic concentration analysis (Fig. 7) indicated that cell culture medium containing L-PLA/HA contained significantly lower $\mathrm{Ca}^{2+}$ concentrations as compared to the other three chemistries, independent of the topography. Regarding the changes in time, it was observed that L-PLA/HA showed an increase in the concentration between day 3 and 7 , remaining stable thereafter. In contrast, the other three materials showed a drop in the concentration between the first two time points, with concentration remaining stable between day 7 and 14 . In line with $\mathrm{Ca}^{2+}$ measurements, lower Pi concentration values were found in L-PLA/HA incubation medium as compared to the other three materials. Furthermore, the $\mathrm{H}$ PLA/HA samples also had lower Pi concentrations than the two polymers, but higher than L-PLA/HA at days 3 and 14. Regarding chronological change, while the concentration of medium containing polymers did not change over time, in composites, an increase between 3 and 7 days and a decrease between 7 and 14 days were 

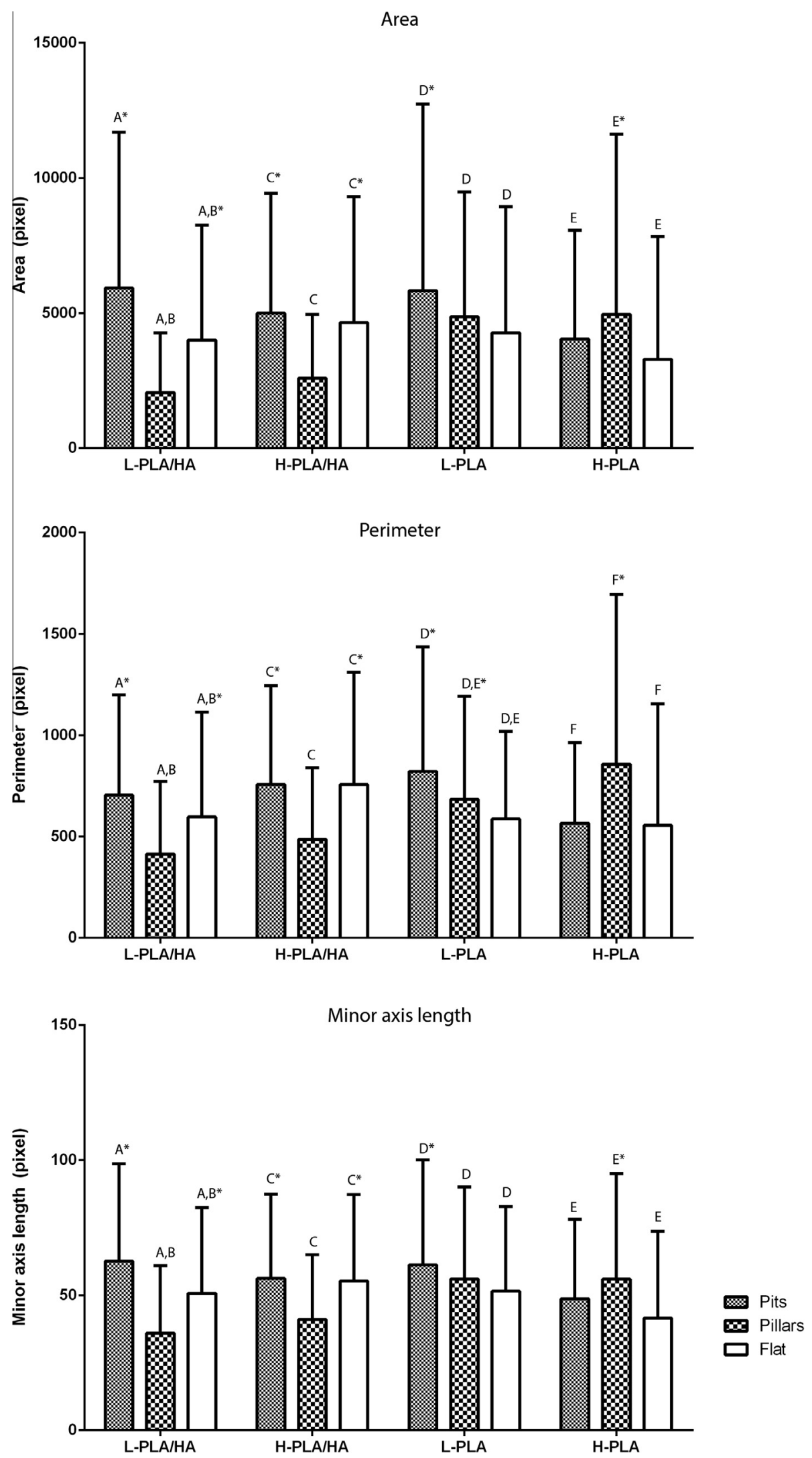

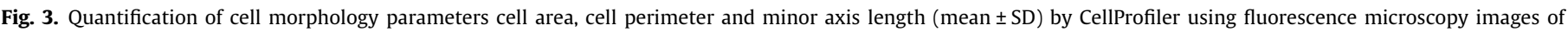

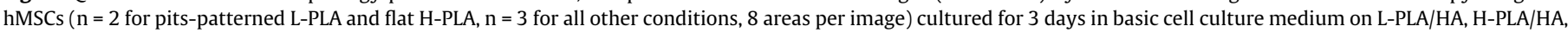

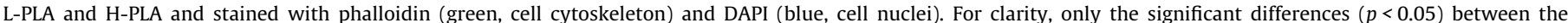

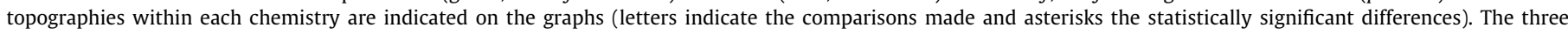

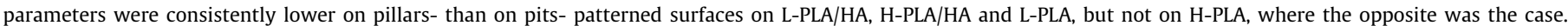
Chemical composition of the materials had a less pronounced effect on cell morphology compared to surface microstructure. 


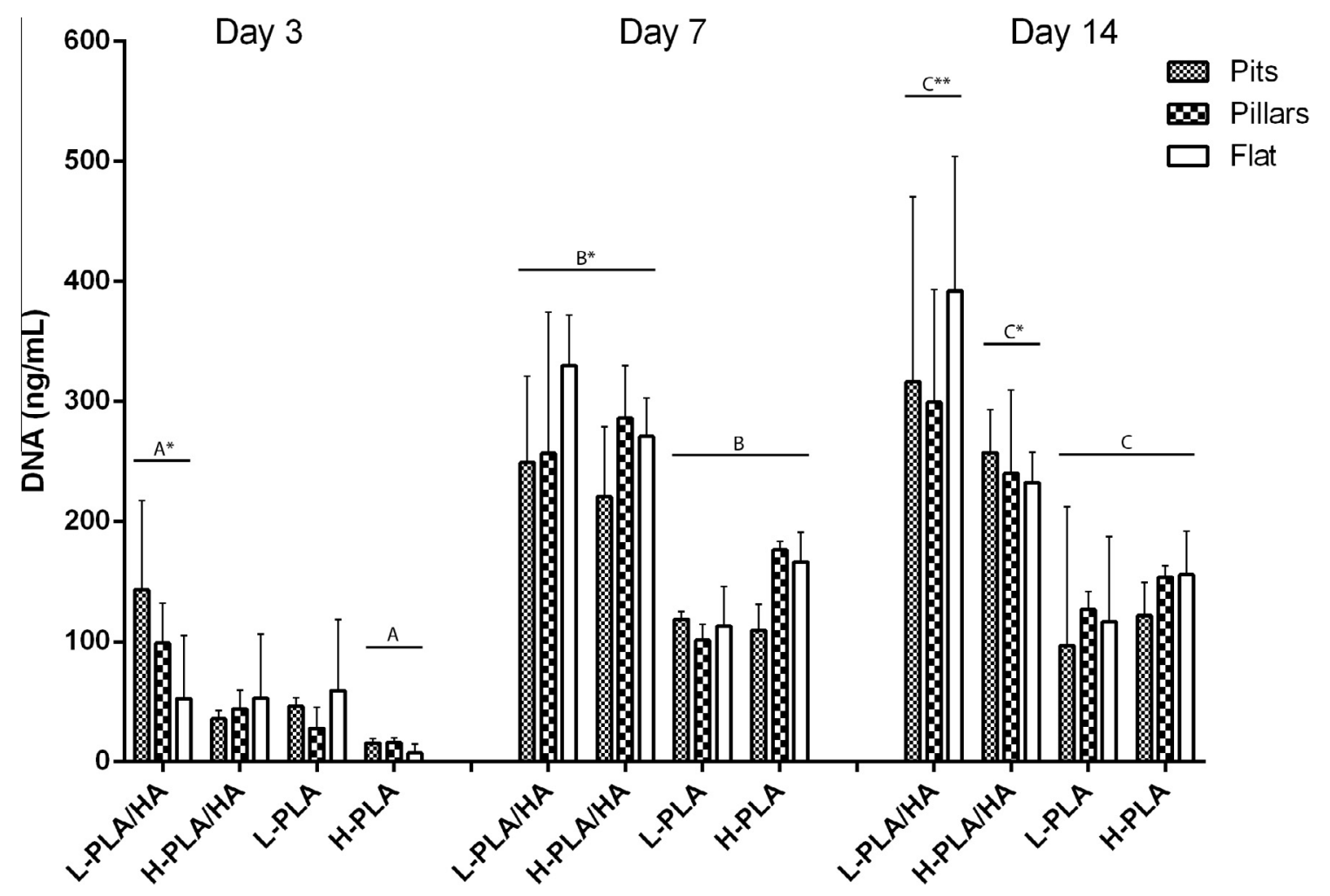

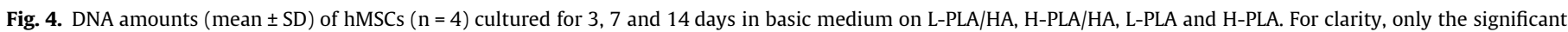

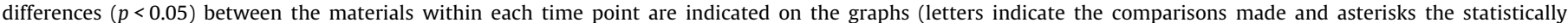

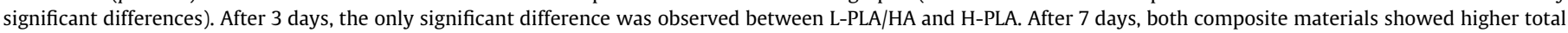

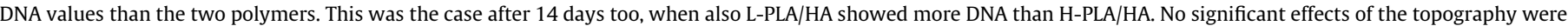
observed.

Day 7

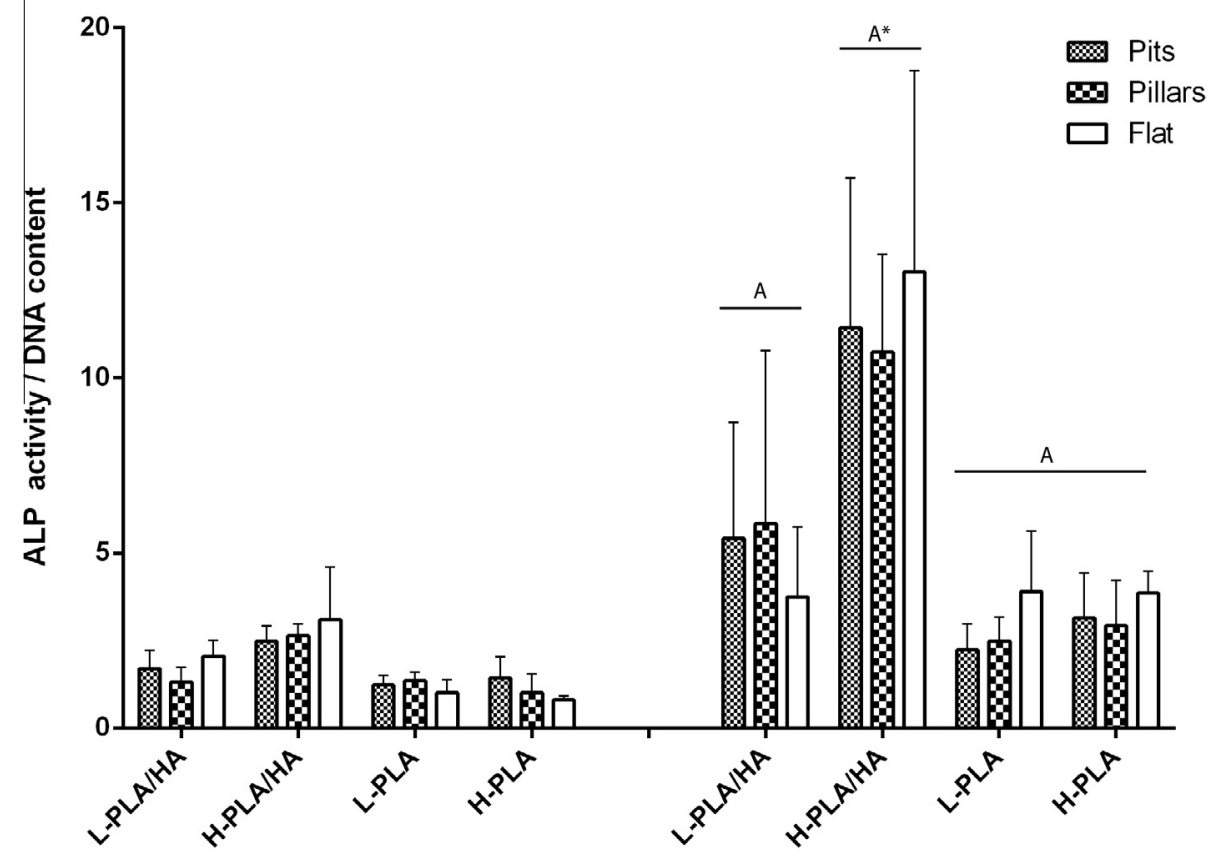

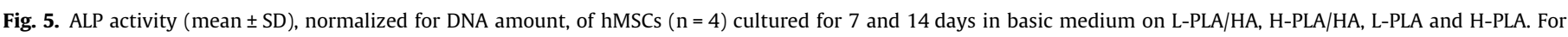

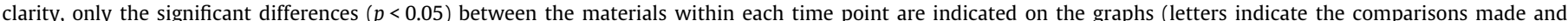

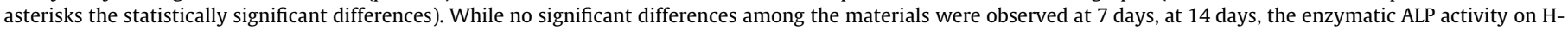
PLA/HA was higher than that on the other three materials. No significant effects of the topography were observed. 

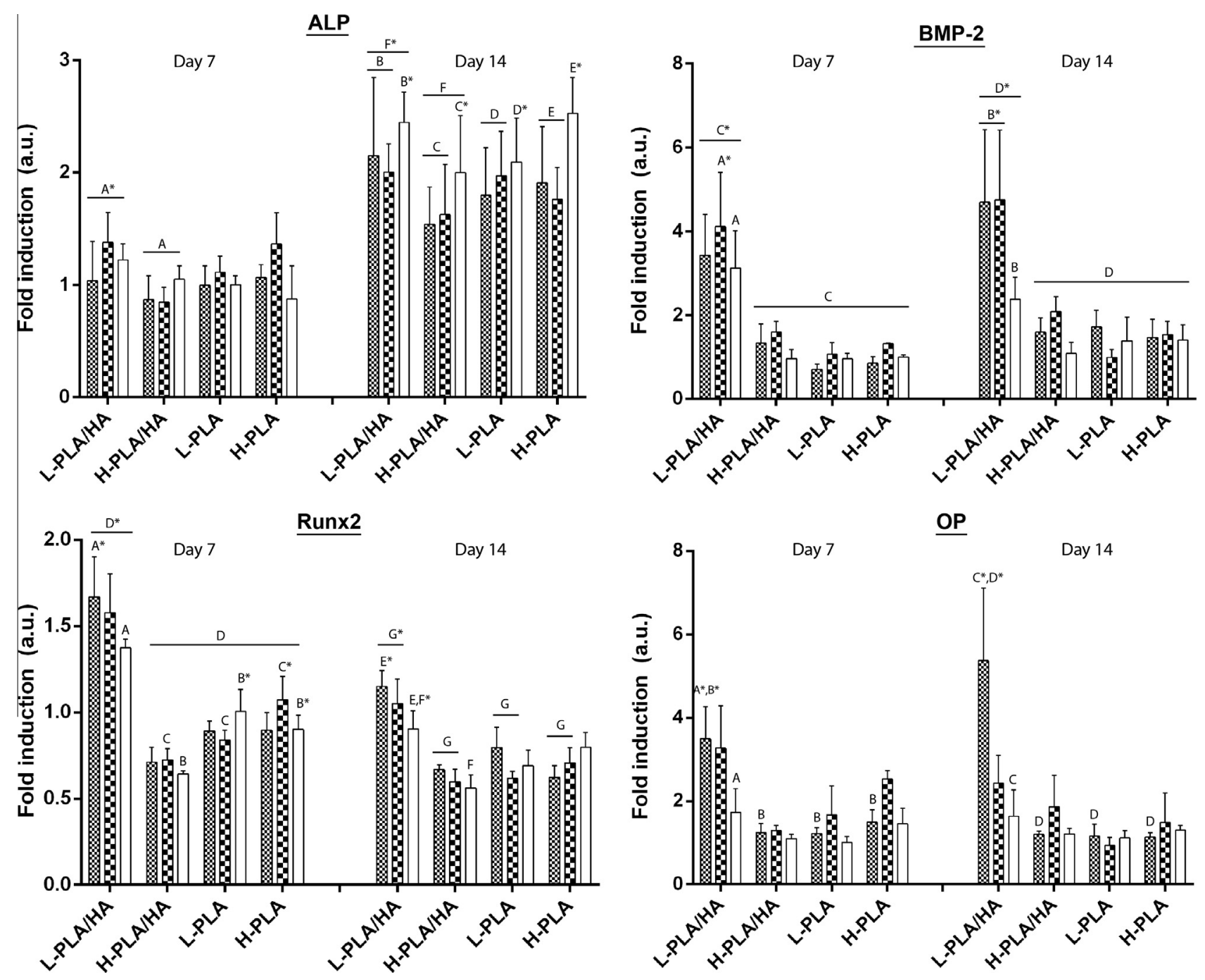

$\underline{\text { Runx2 }}$

Day 14
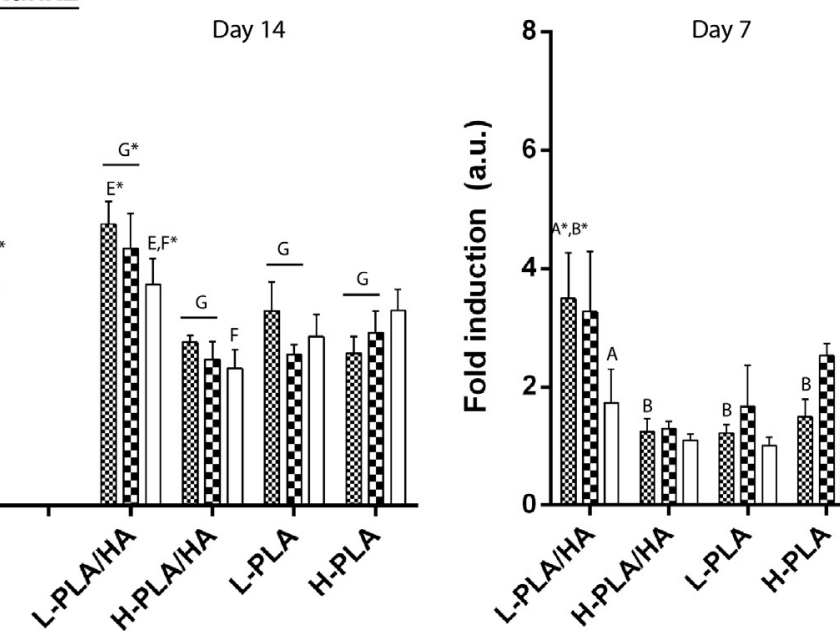

$\underline{\text { OP }}$

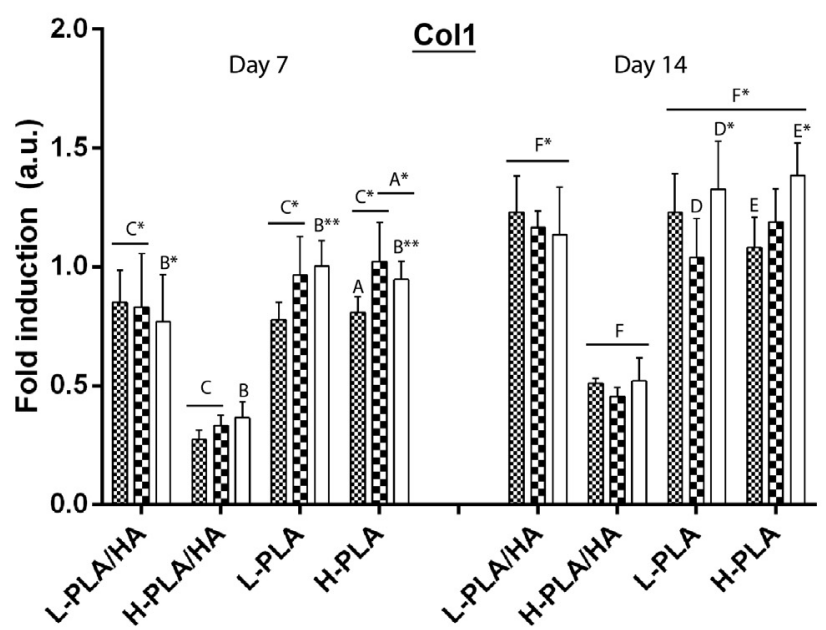

$\infty$ Pillars
Flat

Fig. 6. The normalized expression (mean \pm SD) of a set of osteogenic markers at the mRNA transcription level of hMSCs $(n=3)$ cultured for 7 and 14 days in basic medium on L-PLA/HA, H-PLA/HA, L-PLA and H-PLA, with the expression of cells cultured on H-PLA for 7 days as a calibrator. For clarity, only the significant differences $(p<0.05)$ between the materials within each time point are indicated on the graphs (letters indicate the comparisons made and asterisks the statistically significant differences). A general trend observed was that the expression of osteogenic markers was the highest when cells were cultured on L-PLA/HA, with the exception of Col-1, where no differences were observed between L-PLA/HA and the two polymers. Some topographical effects were seen as well, in particular on the expression of BMP-2 and OP in L-PLA/HA where both topographies and pits pattern respectively showed a higher expression as compared to the unpatterned control. 
Pits

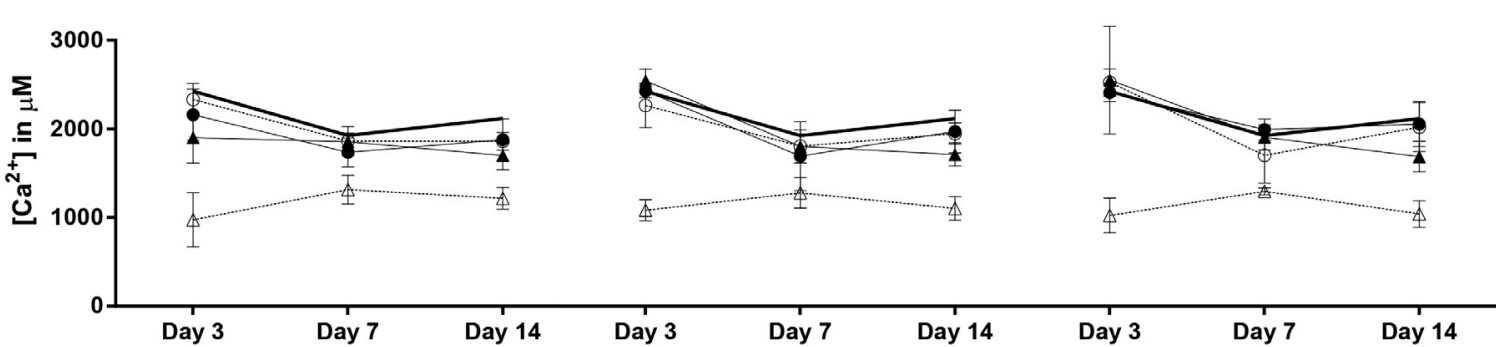

$\triangle \quad$ L-PLA/HA

$\neg$ H-PLA/HA

$\because$ L-PLA

- H-PLA

- Control

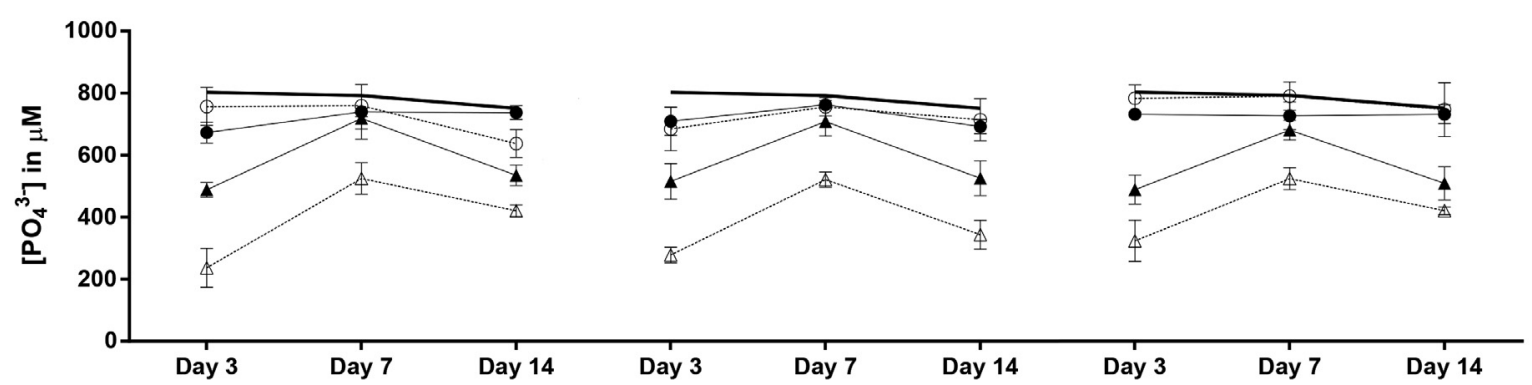

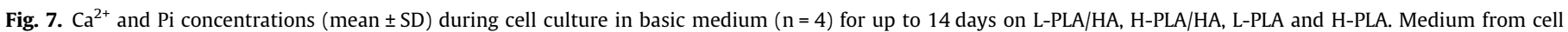

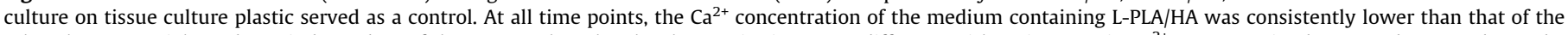

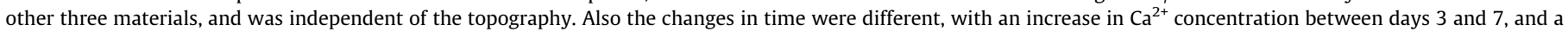

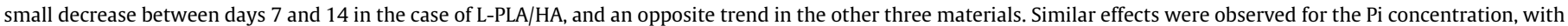

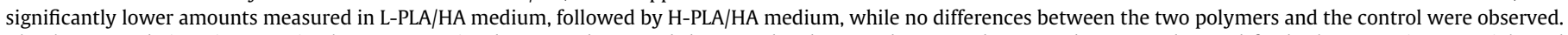

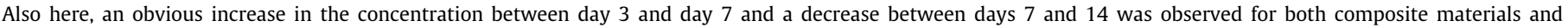
independent of the topography.

observed. Trends observed in OM were similar to those in BM, for both $\mathrm{Ca}^{2+}$ and Pi (Supplementary Fig. 5).

SEM analysis of the materials after 14 days of cell culture in BM (Fig. 8a) exhibited the presence of an extensive number of submicron pores in L-PLA/HA on both flat and patterned surfaces, while no such pores were observed on H-PLA/HA surface. L-PLA samples exhibited cracks, and the surface appeared more flat, with decreased dimensions of pits and pillars. No cracks were observed on H-PLA surface, and although a small decrease of the surface feature dimensions was seen, the surface appeared little affected. No obvious mineral deposits were observed on any of the substrates. The EDS elemental analysis of the two composite materials (Fig. $8 \mathrm{~b}$ ) showed that $\mathrm{P} / \mathrm{C}$ and $\mathrm{Ca} / \mathrm{C}$ ratios increased for both $\mathrm{L}-$ PLA/HA and H-PLA/HA during 14-day cell culture, while the Ca/P remained fairly constant.

\section{Discussion}

This study was an attempt to combine biomaterials that are already used as bone graft substitutes and tools from microtechnology to distinguish between the effects of the chemical composition and surface microstructure on the attachment, proliferation and osteogenic differentiation of clinically relevant hMSCs. Composite materials are commonly used with the aim to exploit the bioactivity of CaPs, while compensating for their intrinsic brittleness. Soft embossing was used to successfully transfer the micropatterns, initially created using laser micromachining, into both polymeric and composite substrates, regardless of the molecular weight of the polymer.

Here, we selected pits and pillars, both to test the direct effect of the topography on the cells but also because it was expected that local ionic concentrations of $\mathrm{Ca}^{2+}$ and $\mathrm{Pi}$ in the patterned composites may be different between the two topographies. This soft embossing technique can, however, be used for a wide range of structures including biomimetic ones [24], and can be applied to different polymers. For example, we have used it to pattern the surface of polystyrene with features of different scales and levels of order (Supplementary Fig. 6).

The analysis of the parameters of cell morphology revealed that both the chemical composition and the topographical features had an effect. The three selected parameters, cell area (the actual number of pixels in the selected region), perimeter (the total number of pixels around the boundary of the selected region) and minor axis length (the length (in pixels) of the minor axis of the ellipse that has the same normalized second central moments as the region) are all related to the cell spreading. In general, the spreading of the cells was more pronounced on the pits- than on pillarspatterned substrates. This observation was, however, dependent on the surface chemistry. While the spreading on pillarspatterned composites was significantly less pronounced as compared to pits-patterned and unpatterned composites, on L-PLA, this difference was smaller, and on H-PLA even an opposite trend was observed, with a more pronounced spreading on pillars- than on pits-patterned and flat H-PLA. This suggests that the cell morphology is also affected, to a different extent, by the molecular weight of the polymer and by the presence of CaP. While there is no definitive correlation between cell morphology and its fate, previous studies have suggested that increased cell spreading facilitates the osteogenic differentiation [51,52]. For example, in a study by Chen et al. it was shown that hMSCs that attach, flatten and spread differentiate along the osteogenic lineage, while a restriction in cell size induces adipogenesis [52]. On the other hand, in a study by Unadkat et al., where a high-throughput screening of a library of topographies on PLA was performed, it was shown that the cells with the highest ALP expression actually had a smaller cell area and perimeter as compared to the cells cultured on flat control [20]. In another study, it was shown that when hMSCs were cultured on microcontact-printed substrates with similar size but small differences in geometrical shape, osteogenic differentiation was promoted on shapes that increased the cytoskeletal tension 
a
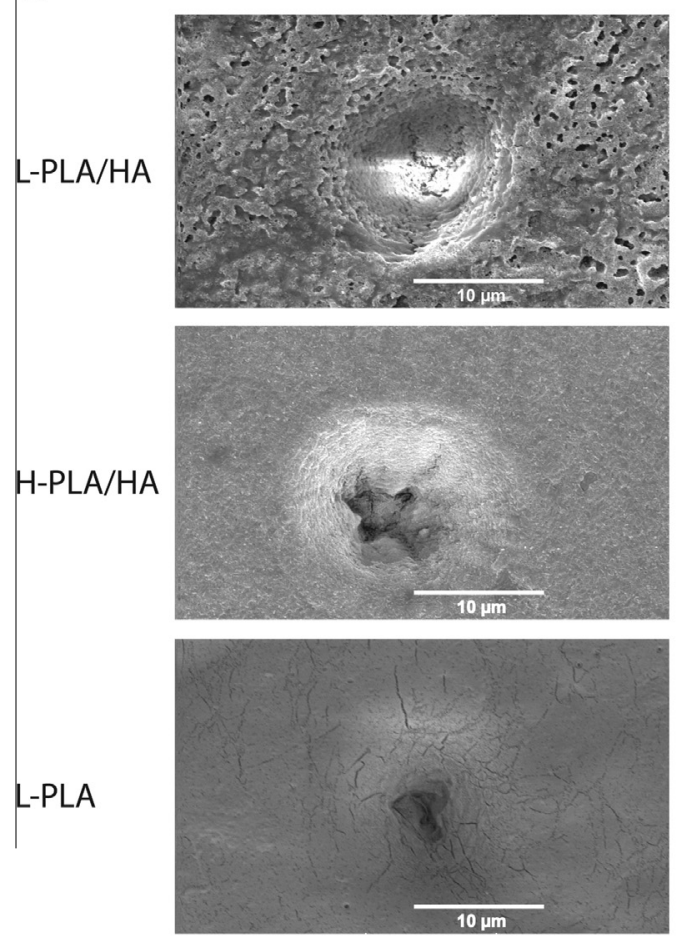

L-PLA

$10 \mathrm{p}$

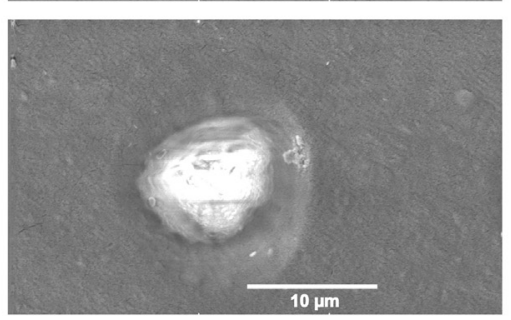

Pillars
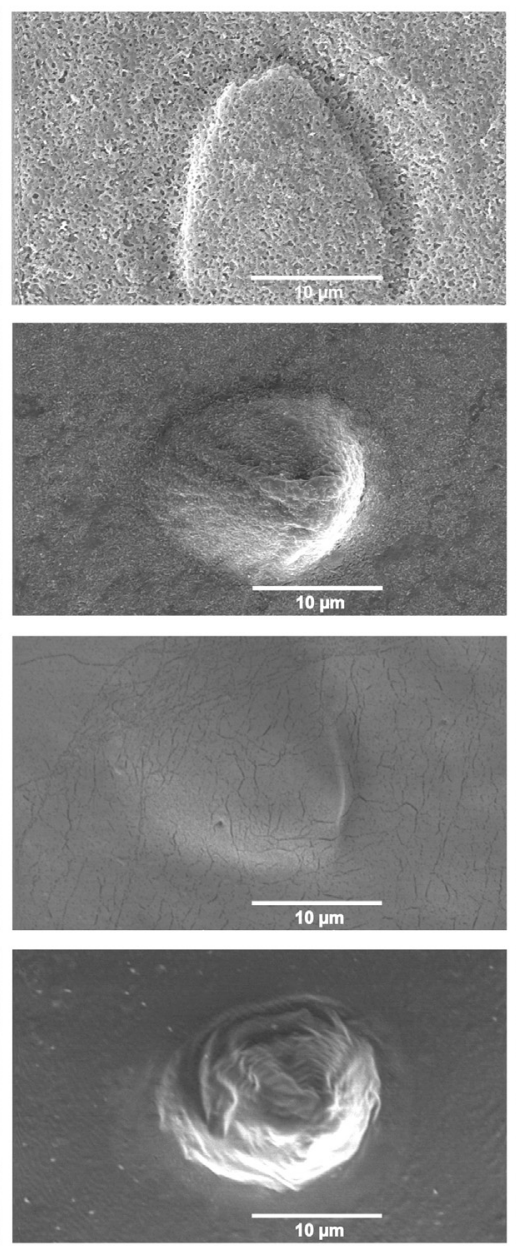

Flat
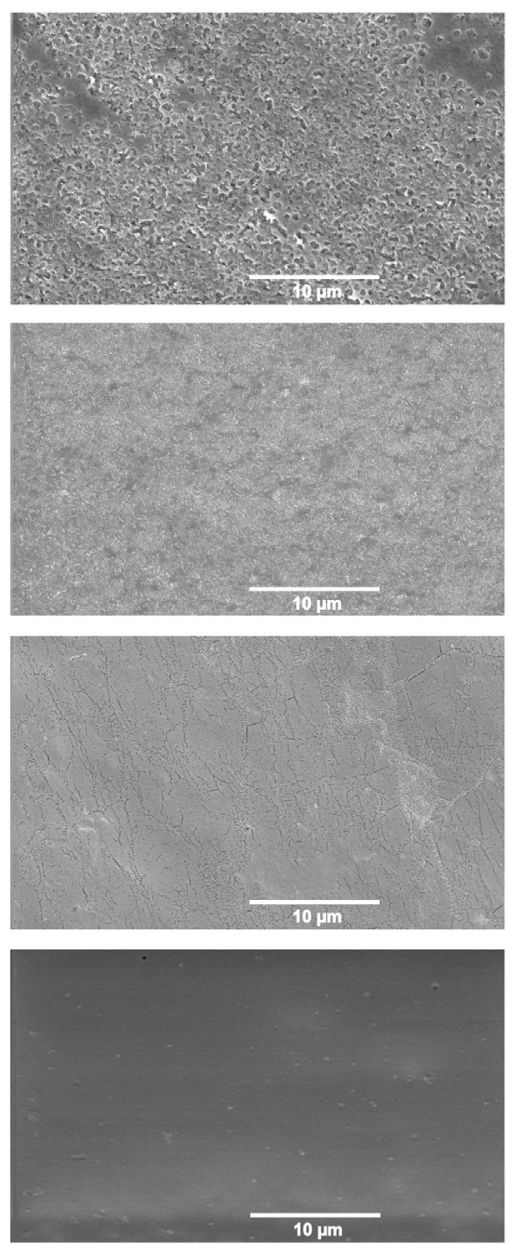

b
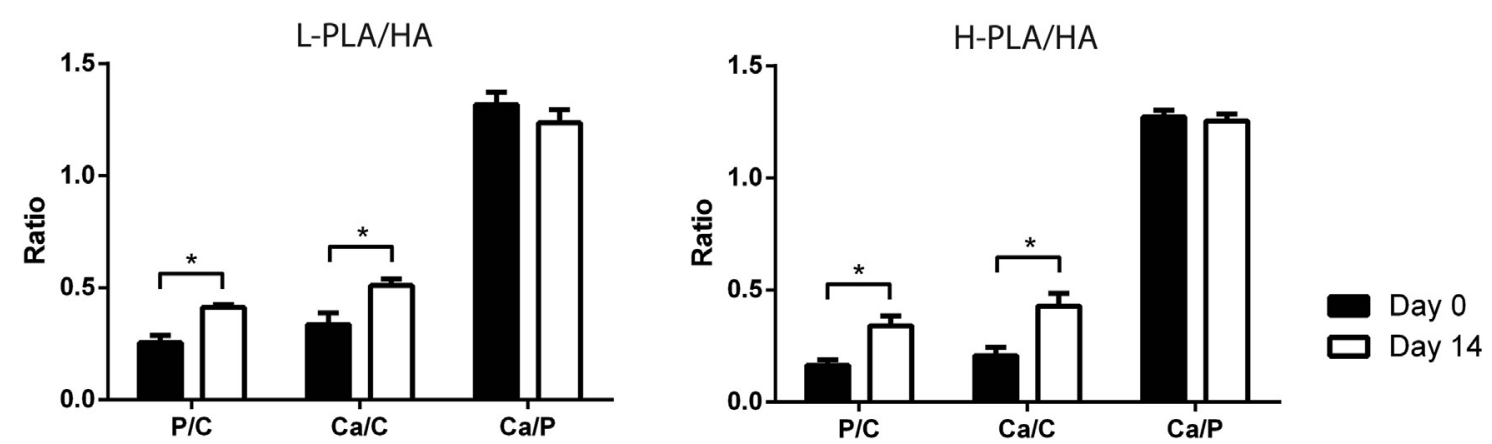

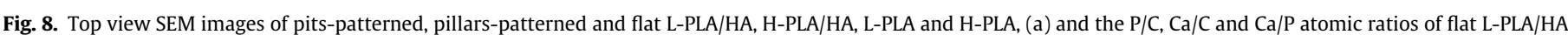

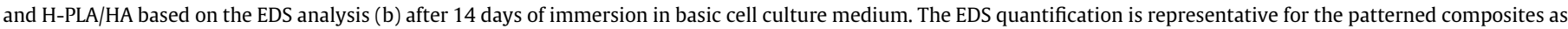

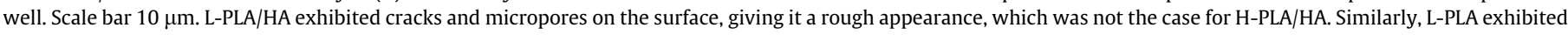

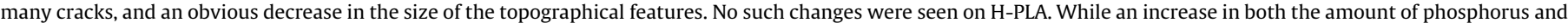
calcium were observed for both composites, no significant changes in $\mathrm{Ca} / \mathrm{P}$ ratio were observed.

[53]. Treiser et al. confirmed the importance of cytoskeleton in shape-guiding the hMSCs differentiation towards the osteogenic lineage [54].

Surface micropatterns did not appear to have an effect on cell proliferation. Reports exist on the effect of surface topography on the proliferation of hMSCs [55-57], however, in these studies, either titanium or titania/alumina ceramics and nanoscale topographical features were tested. While we did not observe an effect of the surface structure, the effect of material chemistry was evident. DNA amounts of cells cultured on the composites, and in particular on L-PLA/HA, were higher than when cells were cultured on either polymer. Conflicting reports exist regarding the effect of PLA/HA composite on the proliferation of hMSCs [44,58], which suggests that other properties, apart from the presence of the ceramic phase, are also of influence on cell growth. Regarding the more specific chemical effect, in recent studies, it was demonstrated that elevated concentrations of $\mathrm{Ca}^{2+}$ in cell culture medium, significantly enhanced the proliferation of hMSCs [21,59]. In an earlier study, in which the materials similar to L-PLA and L-PLA/HA used here were investigated, the support of hMSC proliferation was 
observed [44]. Furthermore, it was shown that $\mathrm{pH}$ evolution upon immersion of the materials into a buffered simulated physiological solution, remained constant in the case of the polymer, and decreased with a value of approximately 1 in the case of the composite. Considering that the cell culture medium is also buffered, it is not plausible that the drop in the $\mathrm{pH}$ of the medium in the presence of PLA may have had a negative effect on cell proliferation, and therefore, the presence of the ceramic itself, and the released ions is most probably responsible for the enhanced proliferation.

The osteogenic differentiation of the cells appeared to be affected by both the chemical composition and the topography, with the latter effect being much less pronounced. Furthermore, the extent of the effect was dependent on the markers used. While the ALP enzymatic activity appeared to be somewhat affected by the chemistry of the substrate, with cells cultured on H-PLA/HA showing higher values than those on the other substrates, at the mRNA transcript level, the differences in ALP expression were very small. A significant effect was observed for the type of medium, where the addition of dexamethasone enhanced the expression and activity of ALP, which is a well-known effect [59-61], whereas the effects of material chemistry or surface structure were nonexistent or too small to have a biological meaning. The materials had a much stronger effect on the mRNA expression of BMP-2 and $O P$, where an upregulation of both markers was observed when hMSCs were cultured on L-PLA/HA as compared to the other three materials. This effect was previously shown for L-PLA/HA PLA comparison after 14 days of culture [24]. The effects of the substrate chemistry were also observed on the expression of Runx2 and Col1, however, the expression of these markers was in general low, with maximum differences of 1.5-fold, and therefore had little biological significance. Interestingly, the effects of the chemistry were observed when cells were cultured in BM, and the expression was strongly downregulated upon the addition of dexamethasone to the medium, which is in accordance with previous studies with CaP materials [21,62]. An effect of the surface structure was observed in the case of the $O P$ and $B M P-2$ expression on L-PLA/ $\mathrm{HA}$, where either the pits-patterned or both the pits- and the pillars patterned substrates showed a higher expression than the unpatterned control. Surface structure effects on Runx2 and Col1 were very small.

Regarding the effect of the chemical composition, previous studies have shown that both the amount of $\mathrm{CaP}$ [32] in a composite material and the molecular weight of the polymer used [25] are determinant for its bioactivity in vivo. A lower molecular weight of the polymer has been suggested to lead to more swelling of the composite, an enhanced degradation of the polymer and more exposure of the CaP to the environment, eventually leading to ectopic bone formation [25]. In another study, it was shown that locally elevated levels of Pi led to collagen mineralization, a process which is of great importance in bone regeneration [22]. In vitro, the expression of $B M P-2$ and $O P$ was enhanced at elevated $\mathrm{Ca}^{2+}$ and/ or Pi levels $[21,59]$.

In the current study, the measurements of the concentrations of the two ions consistently showed lower values of both in the media containing L-PLA/HA as compared to the other three materials. Similar observations were made previously when CaP containing materials were shown to deplete the medium of $\mathrm{Ca}^{2+}$ and $\mathrm{Pi}[44,63]$. Interestingly, this was only the case when the medium was saturated with $\mathrm{Ca}^{2+}$ and/or Pi, like in the case of cell culture medium or simulated body fluid [44]. In media that are initially not saturated with these ions, such as simulated physiological solution of phosphate buffered saline, the release of the ions was observed instead $[25,44]$. It should be noted that the colorimetric method used in the current study to measure $\mathrm{Ca}^{2+}$ and Pi concentrations may not be sensitive enough to precisely measure low release levels in a medium that is already highly saturated with both ions. Nevertheless, the relative differences in the released amounts should give a reliable indication of the differences in the behavior of the four materials tested.

SEM micrographs after cell culture showed that L-PLA/HA exhibited a rough structure with cracks suggesting swelling, degradation and erosion, and plausibly the release of $\mathrm{Ca}^{2+}$ and $\mathrm{Pi}$ ions. This process could plausibly lead to the accumulation of $\mathrm{Ca}^{2+}$ and/or Pi ions in the form of complexes with e.g. serum proteins, although we do not have evidence for this. While the concentration of the two ions in the bulk of the medium was lower in the case of L-PLA/HA as compared to the other materials, the ionic concentrations in the vicinity of the material may be higher than in the bulk, possibly explaining the positive effect on the expression of calcium-responsive genes. Measuring this local concentration is, however, not possible using the conventional elemental analytical techniques.

Regarding the independent surface microstructure effects, to the best of our knowledge, no direct comparison exists between microsized pits and pillars on the osteogenic differentiation of hMSCs. Previous studies have shown that surface microcavities supported osteogenic differentiation of MSCs derived from human dental pulp and induced superior bone formation as compared to cells cultured on a smooth substrate [41]. Another report demonstrated that mineral deposition by osteoblasts was enhanced on the surfaces containing pits in vitro and in vivo [42]. Both these studies were, however, performed with different type of cells and using different materials. As discussed before, the relationship between hMSCs shape and osteogenic differentiation has been previously suggested to lie in cell spreading and/or in cytoskeletal tension [52-54]. While we did not specifically study the latter phenomenon in the current study, the possible effect of cell spreading (more pronounced on pits-patterned as compared to pillars-patterned and unpatterned composites) was not apparent from the expression of osteogenic markers. Indeed, the effects of micropatterns were only obvious in the case of L-PLA/HA and only for BMP-2 and $O P$ expression, however, not only pits-patterned but also the pillars-patterned substrates showed a higher expression as compared to the unpatterned composite.

Taken together, the results of this study showed that the presence of $\mathrm{CaP}$ had the most pronounced effect on the proliferation and osteogenic differentiation of hMSCs, although there was an effect of micropatterns as well, in particular in the case of L-PLA/ HA. Although we have specifically focused on the chemical and microstructural properties, it is difficult to completely exclude possible effects of other properties, such as stiffness or surface charge, which may also differ between the two types of composite/polymer. This again shows that it is very difficult to separate individual properties of functional biomaterials and warrants further research. Nevertheless, this study contributes to strategies that focus on rational design of synthetic biomaterials for biomedical applications, whereby optimal properties for a desired response are first identified and then combined to obtain improved functional biomaterials.

\section{Conclusion}

This study demonstrated that combining ceramic/polymer composite materials based on a polymer with different molecular weights, with soft embossing is a successful way to decouple the individual effects of chemical composition and surface microstructure on the behavior of hMSCs. While surface micropatterns had a strong effect on cell attachment and morphology, the effect of chemistry, i.e. (the extent of) the presence of CaP had a more pronounced effect on cell proliferation and osteogenic differentiation, 
in particular in the case of calcium-responsive genes. The data from this study form a valuable input for designing improved synthetic bone graft substitutes.

\section{Acknowledgements}

Financial support by the TeRM Smart Mix Program of the Netherlands Ministry of Education, Culture and Science (CD), the Sci-Tech Development Program of Jinan City (201221055), the Medical Sci-Tech Development Program of Jinan City (2008-30), the Open Foundation of Shandong Provincial Key Laboratory of Oral Tissue Regeneration (SDKQ201504) (LS), and The Netherlands Institute for Regenerative Medicine (DB) is acknowledged. This project has been in part made possible with the support of the Dutch Province of Limburg. Nick Beijer from the University of Twente is acknowledged for his help with the CellProfiler analysis.

\section{Appendix A. Supplementary data}

Supplementary data associated with this article can be found, in the online version, at http://dx.doi.org/10.1016/j.actbio.2016.06. 018.

\section{References}

[1] R. Balint, N.J. Cassidy, S.H. Cartmell, Conductive polymers: towards a smart biomaterial for tissue engineering, Acta Biomater. 10 (2014) 2341-2353.

[2] S.J. Buwalda, K.W. Boere, P.J. Dijkstra, J. Feijen, T. Vermonden, W.E. Hennink, Hydrogels in a historical perspective: from simple networks to smart materials, J. Controlled Release 190 (2014) 254-273.

[3] Z. Li, X.J. Loh, Water soluble polyhydroxyalkanoates: future materials for therapeutic applications, Chem. Soc. Rev. 44 (2015) 2865-2879.

[4] L. Moroni, A. Nandakumar, F.B. de Groot, C.A. van Blitterswijk, P. Habibovic, Plug and play: combining materials and technologies to improve bone regenerative strategies, J. Tissue Eng. Regener. Med. 9 (7) (2015) 745-759.

[5] A. Bigi, G. Cojazzi, S. Panzavolta, A. Ripamonti, N. Roveri, M. Romanello, K. Noris Suarez, L. Moro, Chemical and structural characterization of the mineral phase from cortical and trabecular bone, J. Inorg. Biochem. 68 (1997) 45-51.

[6] C. Rey, Calcium phosphate biomaterials and bone mineral. Differences in composition, structures and properties, Biomaterials 11 (1990) 13-15.

[7] C.J. Damien, J.R. Parsons, Bone graft and bone graft substitutes: a review of current technology and applications, J. Appl. Biomater. 2 (1991) 187-208.

[8] N. Dobelin, R. Luginbuhl, M. Bohner, Synthetic calcium phosphate ceramics for treatment of bone fractures, Chimia 64 (2010) 723-729.

[9] A.M. Barradas, H. Yuan, C.A. van Blitterswijk, P. Habibovic, Osteoinductive biomaterials: current knowledge of properties, experimental models and biological mechanisms, Eur. Cells Mater. 21 (2011) 407-429. discussion 29.

[10] P. Habibovic, H. Yuan, C.M. van der Valk, G. Meijer, C.A. van Blitterswijk, K. de Groot, 3D microenvironment as essential element for osteoinduction by biomaterials, Biomaterials 26 (2005) 3565-3575.

[11] H. Yuan, C.A. Van Blitterswijk, K. De Groot, J.D. De Bruijn, A comparison of bone formation in biphasic calcium phosphate (BCP) and hydroxyapatite (HA) implanted in muscle and bone of dogs at different time periods, J. Biomed. Mater. Res. Part A 78 (2006) 139-147.

[12] H. Yuan, C.A. Van Blitterswijk, K. De Groot, J.D. De Bruijn, Cross-species comparison of ectopic bone formation in biphasic calcium phosphate (BCP) and hydroxyapatite (HA) scaffolds, Tissue Eng. 12 (2006) 1607-1615.

[13] N.L. Davison, X. Luo, T. Schoenmaker, V. Everts, H. Yuan, F. Barrère-de Groot, J. D. de Bruijn, Submicron-scale surface architecture of tricalcium phosphate directs osteogenesis in vitro and in vivo, Eur. Cells Mater. 27 (2014) 281-297.

[14] H. Yuan, H. Fernandes, P. Habibovic, J. de Boer, A.M. Barradas, A. de Ruiter, W.R. Walsh, C.A. van Blitterswijk, J.D. de Bruijn, Osteoinductive ceramics as a synthetic alternative to autologous bone grafting, Proc. Nat. Acad. Sci. U.S.A. 107 (2010) 13614-13619.

[15] P. Habibovic, M.C. Kruyt, M.V. Juhl, S. Clyens, R. Martinetti, L. Dolcini, N. Theilgaard, C.A. van Blitterswijk, Comparative in vivo study of six hydroxyapatite-based bone graft substitutes, J. Orthop. Res. 26 (2008) 13631370.

[16] P. Habibovic, H. Yuan, M. van den Doel, T.M. Sees, C.A. van Blitterswijk, K. de Groot, Relevance of osteoinductive biomaterials in critical-sized orthotopic defect, J. Orthop. Res. 24 (2006) 867-876.

[17] C.J. Bettinger, B. Orrick, A. Misra, R. Langer, J.T. Borenstein, Microfabrication of poly (glycerol-sebacate) for contact guidance applications, Biomaterials 27 (2006) 2558-2565.

[18] A. Curtis, C. Wilkinson, Topographical control of cells, Biomaterials 18 (1997) $1573-1583$.

[19] M.J. Dalby, N. Gadegaard, R. Tare, A. Andar, M.O. Riehle, P. Herzyk, C.D. Wilkinson, R.O. Oreffo, The control of human mesenchymal cell differentiation using nanoscale symmetry and disorder, Nat. Mater. 6 (2007) 997-1003.

[20] H.V. Unadkat, M. Hulsman, K. Cornelissen, B.J. Papenburg, R.K. Truckenmuller A.E. Carpenter, M. Wessling, G.F. Post, M. Uetz, M.J. Reinders, D. Stamatialis, C. A. van Blitterswijk, J. de Boer, An algorithm-based topographical biomaterials library to instruct cell fate, Proc. Nat. Acad. Sci. U.S.A. 108 (2011) 16565 16570.

[21] C.B. Danoux, D.C. Bassett, Z. Othman, A.I. Rodrigues, R.L. Reis, J.E. Barralet, C.A van Blitterswijk, P. Habibovic, Elucidating the individual effects of calcium and phosphate ions on hMSCs by using composite materials, Acta Biomater. 17 (2015) 1-15.

[22] P. Habibovic, D.C. Bassett, C.J. Doillon, C. Gerard, M.D. McKee, J.E. Barralet, Collagen biomineralization in vivo by sustained release of inorganic phosphate ions, Adv. Mater. 22 (2010) 1858-1862.

[23] G. Mattei, C. Ferretti, A. Tirella, A. Ahluwalia, M. Mattioli-Belmonte, Decoupling the role of stiffness from other hydroxyapatite signalling cues in periosteal derived stem cell differentiation, Sci. Rep. 5 (2015) 10778.

[24] C. Danoux, L. Sun, G. Kocer, Z.T. Birgani, D. Barata, J. Barralet, C. van Blitterswijk, R. Truckenmuller, P. Habibovic, Development of highly functional biomaterials by decoupling and recombining material properties, Adv. Mater. 28 (9) (2016) 1803-1808.

[25] D. Barbieri, H. Yuan, X. Luo, S. Fare, D.W. Grijpma, J.D. de Bruijn, Influence of polymer molecular weight in osteoinductive composites for bone tissue regeneration, Acta Biomater. 9 (2013) 9401-9413.

[26] E. Nejati, V. Firouzdor, M. Eslaminejad, F. Bagheri, Needle-like nano hydroxyapatite/poly (l-lactide acid) composite scaffold for bone tissue engineering application, Mater. Sci. Eng., C 29 (2009) 942-949.

[27] X.H. Wang, S. Shi, G. Guo, S.Z. Fu, M. Fan, F. Luo, X. Zhao, Y.Q. Wei, Z.Y. Qian, Preparation and characterization of a porous scaffold based on poly (D, LLactide) and N-Hydroxyapatite by phase separation, J. Biomater. Sci. Polym. Ed. 22 (2011) 1917-1929.

[28] S.I. Jeong, E.K. Ko, J. Yum, C.H. Jung, Y.M. Lee, H. Shin, Nanofibrous poly (lactic acid)/hydroxyapatite composite scaffolds for guided tissue regeneration, Macromol. Biosci. 8 (2008) 328-338.

[29] S. Hasegawa, J. Tamura, M. Neo, K. Goto, Y. Shikinami, M. Saito, M. Kita, T. Nakamura, In vivo evaluation of a porous hydroxyapatite/poly-DL-lactide composite for use as a bone substitute, J. Biomed. Mater. Res. 75 (2005) 567-579.

[30] M.O. Montjovent, L. Mathieu, H. Schmoekel, S. Mark, P.E. Bourban, P.Y. Zambelli, L.A. Laurent-Applegate, D.P. Pioletti, Repair of critical size defects in the rat cranium using ceramic-reinforced PLA scaffolds obtained by supercritical gas foaming, J. Biomed. Mater. Res. Part A 83 (2007) 41-51.

[31] S. Hasegawa, M. Neo, J. Tamura, S. Fujibayashi, M. Takemoto, Y. Shikinami, K. Okazaki, T. Nakamura, In vivo evaluation of a porous hydroxyapatite/poly-DLlactide composite for bone tissue engineering, J. Biomed. Mater. Res. Part A 81 (2007) 930-938.

[32] D. Barbieri, A.J. Renard, J.D. de Bruijn, H. Yuan, Heterotopic bone formation by nano-apatite containing poly(D, L-lactide) composites, Eur. Cells Mater. 19 (2010) 252-261.

[33] A. Khademhosseini, R. Langer, J. Borenstein, J.P. Vacanti, Microscale technologies for tissue engineering and biology, Proc. Nat. Acad. Sci. U.S.A. 103 (2006) 2480-2487.

[34] D. Falconnet, G. Csucs, H. Michelle Grandin, M. Textor, Surface engineering approaches to micropattern surfaces for cell-based assays, Biomaterials 27 (2006) 3044-3063.

[35] Y. Ito, Surface micropatterning to regulate cell functions, Biomaterials 20 (1999) 2333-2342.

[36] Y. Xia, G.M. Whitesides, Soft lithography, Annu. Rev. Mater. Sci. 28 (1998) 153 184

[37] M. Geissler, Y. Xia, Patterning: principles and some new developments, Adv. Mater. 16 (2004) 1249-1269.

[38] G.M. Whitesides, The origins and the future of microfluidics, Nature 442 (2006) 368-373.

[39] J. Le Digabel, M. Ghibaudo, L. Trichet, A. Richert, B. Ladoux, Microfabricated substrates as a tool to study cell mechanotransduction, Med. Biol. Eng Comput. 48 (2010) 965-976.

[40] M. Nikkhah, F. Edalat, S. Manoucheri, A. Khademhosseini, Engineering microscale topographies to control the cell-substrate interface, Biomaterials 33 (2012) 5230-5246.

[41] A. Graziano, R. d’Aquino, M.G. Cusella-De Angelis, G. Laino, A. Piattelli, M Pacifici, A. De Rosa, G. Papaccio, Concave pit-containing scaffold surfaces improve stem cell-derived osteoblast performance and lead to significant bone tissue formation, PLoS ONE 2 (2007) e496.

[42] D.W. Hamilton, B. Chehroudi, D.M. Brunette, Comparative response of epithelial cells and osteoblasts to microfabricated tapered pit topographies in vitro and in vivo, Biomaterials 28 (2007) 2281-2293.

[43] U. Ripamonti, J. Crooks, A.N. Kirkbride, Sintered porous hydroxyapatites with intrinsic osteoinductive activity: geometric induction of bone formation, S. Afr. J. Sci. 95 (1999) 335-343.

[44] C.B. Danoux, D. Barbieri, H. Yuan, J.D. de Bruijn, C.A. van Blitterswijk, P. Habibovic, In vitro and in vivo bioactivity assessment of a polylactic acid/ hydroxyapatite composite for bone regeneration, Biomatter 4 (2014) e27664

[45] M. Hulsman, F. Hulshof, H. Unadkat, B.J. Papenburg, D.F. Stamatialis, R. Truckenmuller, C. van Blitterswijk, J. de Boer, M.J. Reinders, Analysis of highthroughput screening reveals the effect of surface topographies on cellular morphology, Acta Biomater. 15 (2015) 29-38. 
[46] R.G. Thakar, F. Ho, N.F. Huang, D. Liepmann, S. Li, Regulation of vascular smooth muscle cells by micropatterning, Biochem. Biophys. Res. Commun. 307 (2003) 883-890.

[47] S.K. Both, A.J.C. Van der Muijsenberg, C.A. Van Blitterswijk, J. De Boer, J.D. De Bruijn, A rapid and efficient method for expansion of human mesenchymal stem cells, Tissue Eng. 13 (2007) 3-9.

[48] H. Fernandes, A. Mentink, R. Bank, R. Stoop, C. van Blitterswijk, J. de Boer Endogenous collagen influences differentiation of human multipotent mesenchymal stromal cells, Tissue Eng. Part A 16 (2010) 1693-1702.

[49] S.C. Mendes, J.M. Tibbe, M. Veenhof, S.K. Both, F.C. Oner, C. van Blitterswijk, J.D. de Bruijn, Relation between in vitro and in vivo osteogenic potential of cultured human bone marrow stromal cells, J. Mater. Sci. - Mater. Med. 15 (2004) 1123-1128.

[50] A.E. Carpenter, T.R. Jones, M.R. Lamprecht, C. Clarke, I.H. Kang, O. Friman, D.A Guertin, J.H. Chang, R.A. Lindquist, J. Moffat, P. Golland, D.M. Sabatini, Cell Profiler: image analysis software for identifying and quantifying cell phenotypes, Genome Biol. 7 (2006).

[51] W. Song, N. Kawazoe, G. Chen, Dependence of spreading and differentiation of mesenchymal stem cells on micropatterned surface area, J. Nanomater. 2011 (2011) 6.

[52] R. McBeath, D.M. Pirone, C.M. Nelson, K. Bhadriraju, C.S. Chen, Cell shape cytoskeletal tension, and RhoA regulate stem cell lineage commitment, Dev. Cell 6 (2004) 483-495.

[53] K.A. Kilian, B. Bugarija, B.T. Lahn, M. Mrksich, Geometric cues for directing the differentiation of mesenchymal stem cells, Proc. Nat. Acad. Sci. U.S.A. 107 (2010) 4872-4877.

[54] M.D. Treiser, E.H. Yang, S. Gordonov, D.M. Cohen, I.P. Androulakis, J. Kohn, C.S Chen, P.V. Moghe, Cytoskeleton-based forecasting of stem cell lineage fates Proc. Nat. Acad. Sci. U.S.A. 107 (2010) 610-615.

[55] G.M. de Peppo, H. Agheli, C. Karlsson, K. Ekstrom, H. Brisby, M. Lenneras, S. Gustafsson, P. Sjovall, A. Johansson, E. Olsson, J. Lausmaa, P. Thomsen, S. Petronis, Osteogenic response of human mesenchymal stem cells to welldefined nanoscale topography in vitro, Int. J. Nanomed. 9 (2014) 2499-2515.
[56] A.J. Dulgar-Tulloch, R. Bizios, R.W. Siegel, Human mesenchymal stem cell adhesion and proliferation in response to ceramic chemistry and nanoscale topography, J. Biomed. Mater. Res., Part A 90 (2009) 586-594.

[57] U. Hempel, T. Hefti, P. Dieter, F. Schlottig, Response of human bone marrow stromal cells, MG-63, and SaOS-2 to titanium-based dental implant surfaces with different topography and surface energy, Clin. Oral Implants Res. 24 (2013) 174-182.

[58] S. Morelli, S. Salerno, J. Holopainen, M. Ritala, L.D. Bartolo, Osteogenic and osteoclastogenic differentiation of co-cultured cells in polylactic acidnanohydroxyapatite fiber scaffolds, J. Biotechnol. 204 (2015) 53-62.

[59] A.M. Barradas, H.A. Fernandes, N. Groen, Y.C. Chai, J. Schrooten, J. van de Peppel, J.P. van Leeuwen, C.A. van Blitterswijk, J. de Boer, A calcium-induced signaling cascade leading to osteogenic differentiation of human bone marrow-derived mesenchymal stromal cells, Biomaterials 33 (2012) 32053215.

[60] J.N. Beresford, C.J. Joyner, C. Devlin, J.T. Triffitt, The effects of dexamethasone and 1,25-dihydroxyvitamin D3 on osteogenic differentiation of human marrow stromal cells in vitro, Arch. Oral Biol. 39 (1994) 941-947.

[61] S. Walsh, G.R. Jordan, C. Jefferiss, K. Stewart, J.N. Beresford, High concentrations of dexamethasone suppress the proliferation but not the differentiation or further maturation of human osteoblast precursors in vitro: relevance to glucocorticoid-induced osteoporosis, Rheumatology 40 (2001) 74-83.

[62] Z. Tahmasebi Birgani, C.A. van Blitterswijk, P. Habibovic, Monolithic calcium phosphate/poly(lactic acid) composite versus calcium phosphate-coated poly (lactic acid) for support of osteogenic differentiation of human mesenchymal stromal cells, J. Mater. Sci. Mater. Med. 27 (2016) 54.

[63] A.M. Barradas, V. Monticone, M. Hulsman, C. Danoux, H. Fernandes, Z. Tahmasebi Birgani, F. Barrere-de Groot, H. Yuan, M. Reinders, P. Habibovic, C. van Blitterswijk, J. de Boer, Molecular mechanisms of biomaterial-driven osteogenic differentiation in human mesenchymal stromal cells, Integr. Biol. 5 (2013) 920-931. 